\title{
PARP inhibitors for BRCA1/2-mutated and sporadic ovarian cancer: current practice and future directions
}

\author{
G E Konecny ${ }^{\star, 1}$ and R S Kristeleit ${ }^{2}$ \\ ${ }^{1}$ Division of Hematology-Oncology, Department of Medicine, David Geffen School of Medicine, University of California \\ Los Angeles, 2825 Santa Monica Blvd., Suite 200, Santa Monica, CA 90404-2429, USA and ²Department of Oncology, University \\ College London Cancer Institute, University College London, Paul Gorman Building, Huntley Street, London, WC1E 6BT, UK
}

Poly(ADP-ribose) polymerase (PARP) inhibitors cause targeted tumour cell death in homologous recombination (HR)-deficient cancers, including BRCA-mutated tumours, by exploiting synthetic lethality. PARP inhibitors are being evaluated in late-stage clinical trials of ovarian cancer (OC). Recently, olaparib was the first PARP inhibitor approved in the European Union and United States for the treatment of advanced BRCA-mutated OC. This paper reviews the role of BRCA mutations for tumorigenesis and PARP inhibitor sensitivity, and summarises the clinical development of PARP inhibitors for the treatment of patients diagnosed with OC. Among the five key PARP inhibitors currently in clinical development, olaparib has undergone the most extensive clinical investigation. PARP inhibitors have demonstrated durable antitumour activity in BRCA-mutated advanced OC as a single agent in the treatment and maintenance setting, particularly in platinum-sensitive disease. PARP inhibitors are well tolerated; however, further careful assessment of moderate and late-onset toxicity is mandatory in the maintenance and adjuvant setting, respectively. PARP inhibitors are also being evaluated in combination with chemotherapeutic and novel targeted agents to potentiate antitumour activities. Current research is extending the use of PARP inhibitors beyond BRCA mutations to other sensitising molecular defects that result in HR-deficient cancer, and is defining an HR-deficiency signature. Trials are underway to determine whether such a signature will predict sensitivity to PARP inhibitors in women with sporadic OC.

\section{INTRODUCTION}

Current efforts to treat $B R C A$-associated ovarian cancer (OC) with poly(ADP-ribose) polymerase (PARP) inhibitors result from $>25$ years of basic and translational cancer research. Recently, olaparib, the first PARP inhibitor to treat $B R C A$ mutation-positive patients, has been approved in the European Union and United States (US). Clinical studies have shown that BRCA1/2-deficient tumours are sensitive to PARP inhibitors and platinum agents (Fong et al, 2009; Byrski et al, 2010). PARP inhibitors are molecules that inhibit the activity of PARP proteins, which are involved in a variety of DNA damage repair pathways. The European Commission granted marketing authorisation for the PARP inhibitor olaparib as monotherapy in the maintenance treatment of adult patients with platinumsensitive, relapsed BRCA-mutated (germline and/or somatic) high-grade serous epithelial ovarian, fallopian tube, or primary peritoneal cancer who are in complete response (CR) or partial response (PR) following platinum-based chemotherapy (Lynparza prescribing information, 2014). In the United States, olaparib received accelerated approval by the Food and Drug Administration (FDA) as monotherapy in patients with deleterious or suspected deleterious germline BRCA-mutated $(g B R C A m)$ advanced OC and who have been treated with three or more prior lines of chemotherapy (Lynparza prescribing information, 2014). Confirmatory phase III trials are underway. This article will review the current role of BRCA proteins and PARP inhibitors in OC, summarise completed and ongoing clinical studies with PARP inhibitors, and outline future directions for this new drug class.

BRCA1/2 and cancer risk. A major development in the treatment of breast cancer and OC was the cloning of the suppressor genes

*Correspondence: Dr GE Konecny; E-mail: gkonecny@mednet.ucla.edu

Received 6 November 2015; revised 2 August 2016; accepted 1 September 2016; published online 13 October 2016 
BRCA1 and BRCA2 (Friedman et al, 1994; Miki et al, 1994; Wooster et al, 1995). BRCA1/2 encode proteins that are involved in homologous recombination (HR) (Farmer et al, 2005). Epidemiologic studies have revealed an association between germline BRCA1/2 (gBRCA1/2) mutations and the development of $\mathrm{OC}$ and breast cancer, and mutation frequencies are estimated to be $5-15 \%$ for patients diagnosed with OC (Ramus and Gayther, 2009) and $10 \%$ for those diagnosed with breast cancer (Neuhausen et al, 2009). However, mutation frequency can be much higher among certain high-risk populations; for example, the mutations are present in $41 \%$ of women of Ashkenazi Jewish decent (Moslehi et al, 2000). Among a general female population, the lifetime risk for development of OC and breast cancer ranges between $1 \%$ and $12 \%$, respectively (National Cancer Institute, 2015a, b). However, for patients harboring a deleterious $\mathrm{g} B R C A 1 / 2$ mutation, the estimated lifetime risk by age 70 for developing OC is $40 \%$ for gBRCA1 mutation carriers and $11-18 \%$ for $g B R C A 2$ mutation carriers, and the risk for developing breast cancer is $57-65 \%$ for gBRCA1 and 45-49\% for gBRCA2 mutation carriers (Antoniou et al, 2003; Chen and Parmigiani, 2007).

Patients with a gBRCA1/2 mutation have inherited a loss-offunction mutation in a single copy of either BRCA1 or BRCA2 in every cell. Although it is understandable that the risk for developing cancer is increased as the remaining second wild-type copy of the gene can be inactivated by a somatic mutation or epigenetic inactivation (Venkitaraman, 2014), it remains unclear why mutations in BRACA1/2 specifically lead to OC or breast cancer; and to a lesser degree, to pancreatic or prostate cancer. Recent evidence indicates that oestrogen controls the survival of $B R C A 1$-deficient cells via a PI3K/NRF2-regulated pathway, which may partially explain the reported occurrence of hormonally driven tumours in patients who carry a BRCA1/2 mutation (Gorrini et al, 2014). Preclinical mouse studies have found that BRCA1 protein interacts with NRF2 and that cells lacking BRCA1 activity accumulate reactive oxygen species resulting in attenuated cell viability (Gorrini et al, 2013). NRF2 is a transcription factor that regulates the antioxidant response ( $\mathrm{Li}$ et al, 2004) and reactivation of NRF2 by oestrogen results in cell survival (Gorrini et al, 2013). NRF2 activity is governed by the activation of PI3K pathway, which promotes oestrogen stimulation of NRF2 activity to compensate for the lack of antioxidant response in the absence of BRCA1 activity (Gorrini et al, 2014).

DNA repair and role of $B R C A$. Currently, six primary pathways have been identified for DNA repair, and they are engaged variably to repair single- (SSB) and double-strand (DSB) DNA breaks resulting from DNA damage (Lee et al, 2014). These repair mechanisms include homologous recombination (HR), nonhomologous end joining (NHEJ), base excision repair, nucleotide excision repair, mismatch repair, and trans-lesional synthesis (Lee et al, 2014). DNA damage can occur in a number of ways including generation of reactive oxygen species, ultraviolet light, ambient and therapeutic irradiation, day-to-day replication errors, and chemical exposures (Lee et al, 2014).

In response to DNA damage, proteins that comprise repair complexes are recruited to the site of damage (Gudmundsdottir and Ashworth, 2006). Loss or reduction of function in proteins involved in these complexes can result in impairment or loss of proper DNA repair. Double-stranded breaks trigger HR, which demonstrates high fidelity, and NHEJ, which is error prone (Lee et al, 2014; Scott et al, 2015). BRCA1/2 proteins mediate what might be the rate limiting step in HR (Farmer et al, 2005) and play a critical step in HR by facilitating the recruitment of RAD51 to single-stranded DNA generated during the HR process (Ciccia and Elledge, 2010; Polo and Jackson, 2011). RAD51 is a component of a complex of factors, which also includes MRE11 and NBS1, that is essential for HR (Stracker and Petrini, 2011). Therefore, cells that lack BRCA1/2 are deficient in HR and demonstrate a high degree of chromosomal instability as well as increased sensitivity to ionising radiation and chemotherapeutic agents that lead to DSBs (Ashworth, 2008). Whether HR or NHEJ occurs to correct DSBs depends upon a number of factors, one of which is the cell-cycle status; HR is used if DSBs arise during the S or G2 stages of mitosis, and NHEJ is utilised if DSBs occur during G1 (Symington and Gautier, 2011; Chapman et al, 2012, 2013; Karanam et al, 2012; Di Virgilio et al, 2013; Escribano-Diaz et al, 2013; Zimmermann et al, 2013). Other factors that influence which mechanism is used to repair DSBs are the complexity of the breaks and the presence of co-factors (Karanam et al, 2012).

PARP function. Poly(ADP-ribose) polymerase 1 is the first identified among a family of enzymes that transfer ADP-ribose moieties from the dinucleotide $\mathrm{NAD}+$ to certain polypeptides resulting in mono- or poly(ADP-ribosylation) (pADPr) of these substrates (Burkle, 2001; Kim et al, 2005; Schreiber et al, 2006). PARP inhibitors are designed to compete with NAD + for the substrate binding to PARP, inhibiting PARP activity (Kim et al, 2005). Poly(ADP-ribose) polymerase 1, PARP2, and PARP3 have all been implicated in DNA repair, with PARP1 being the most abundant (Sousa et al, 2012). Certain types of DNA damage, particularly DNA nicks and DSBs, result in an about a 500-fold increase in PARP1 catalytic activity (Mendoza-Alvarez and Alvarez-Gonzalez, 1993; Mendoza-Alvarez and Alvarez-Gonzalez, 2004; Hassler and Ladurner, 2012). Active PARP1 covalently adds pADPr chains to a number of chromatin proteins, including itself (Althaus and Richter, 1987; Hassler and Ladurner, 2012), which alters the function of the respective proteins (Althaus and Richter, 1987; Realini and Althaus, 1992; Malanga and Althaus, 2004).

PARP1 functions in a number of DNA repair pathways (Rouleau et al, 2010; Curtin, 2012). It has been most extensively studied in base excision repair (de Murcia et al, 1997; Masson et al, 1998; Trucco et al, 1998) in which it facilitates the recruitment and formation of DNA repair complexes, including XRCC1, which in turn promotes SSB repair (Caldecott, 2008; Odell et al, 2013; O'Sullivan et al, 2014). In addition, PARP1 acts in HR by sensing stalled replication forks and recruitment of MRE11 and NBS1 to initiate HR (Schultz et al, 2003; Helleday et al, 2005; Haince et al, 2008; Bryant et al, 2009). PARP1 also adds pADPr to BRCA1 to influence DSB repair during $\mathrm{HR}$ (Hu et al, 2014), and inhibits NHEJ repair by preventing the binding of the Ku proteins to free DNA ends (Wang et al, 2006; Scott et al, 2015). In addition, PARP1 is necessary for the alternative microhomology-mediated end joining repair (Robert et al, 2009; Soni et al, 2014). PARP2 and PARP3 also contribute to DNA repair; PARP2 cooperates with PARP1 to synthesise pADPr and PARP3 inhibits error prone NHEJ (Ame et al, 1999; Schreiber et al, 2002; Rulten et al, 2011).

\section{PARP inhibitor activity}

Synthetic lethality. Genetically, synthetic lethality occurs when two genetic lesions, which are individually not lethal, become lethal when combined in a single organism (or cell). Similarly, cells that are deficient in HR (which is not lethal in itself) are hypersensitive to reduction in PARP activity by PARP inhibitors (Bryant et al, 2005; Farmer et al, 2005; Patel et al, 2011; Scott et al, 2015). Currently there are four models proposed for how PARP inhibitors may instigate synthetic lethality: inhibition of base excision repair, trapping PARP1 on damaged DNA, defective recruitment of BRCA1 to damaged DNA, and activation of error-prone NHEJ (Figure 1).

Base excision repair. Synthetic lethality, observed with BRCA1/2 mutations plus inhibition of PARP activity, may result both from removal of HR, and reduction in base excision repair (Scott et al, 2015) (Figure 1). Under pharmacologic PARP inhibition, SSBs, normally 
A

Single-strand break (SSB) repair

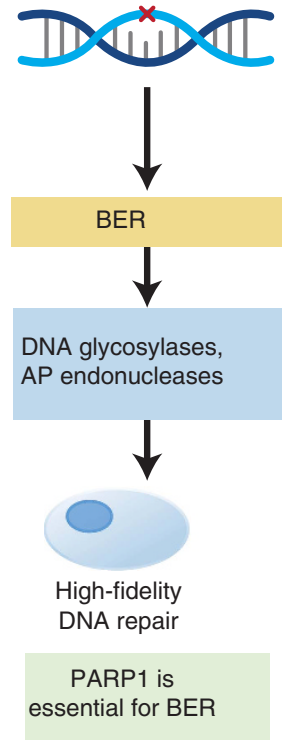

B SSB repair
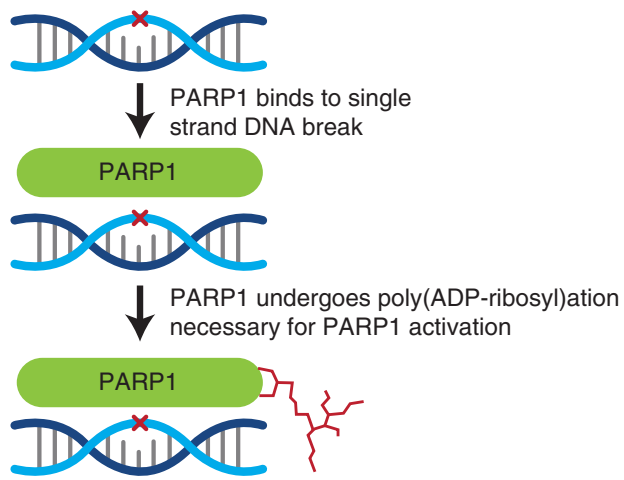

$\downarrow$ Poly(ADP-ribosyl)ated PARP1 recruits DNA

$\checkmark$ repair complexes (BARD1-BRCA1, MRN)

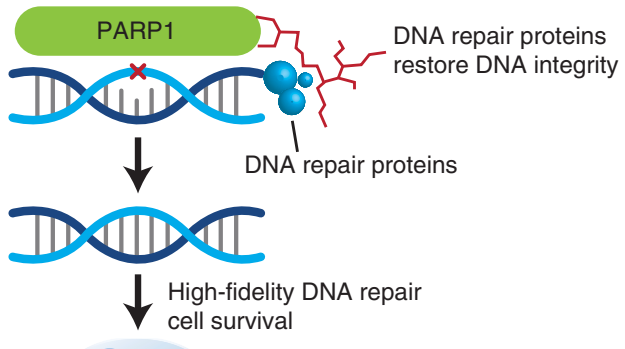

High-fidelity DNA repair and fine-tunes HR

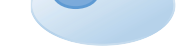

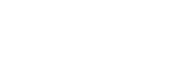

Double-strand break (DSB) repair

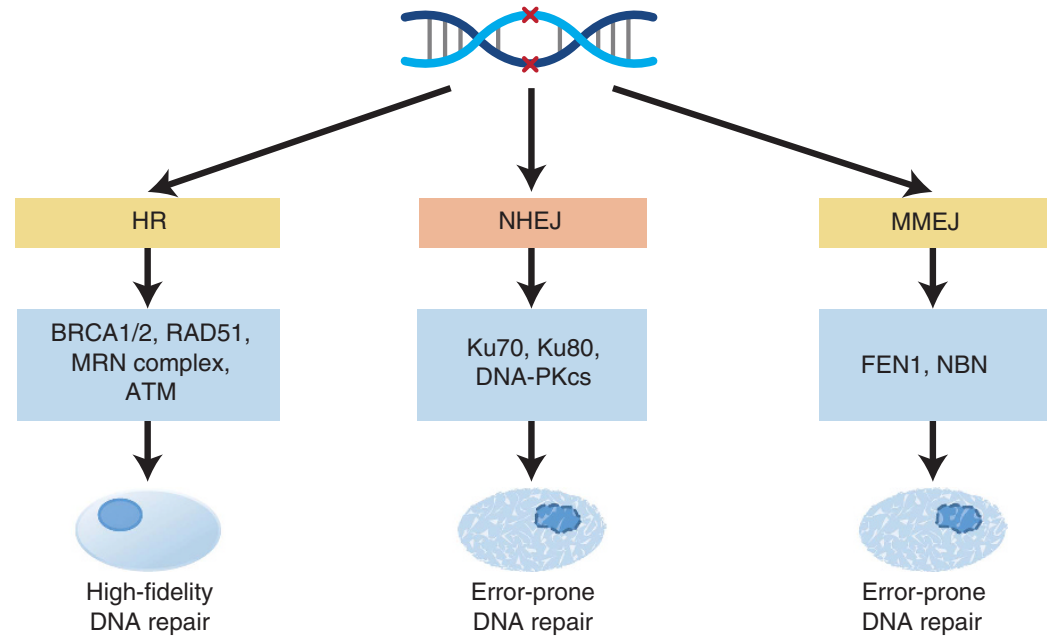

PARP1 contributes to (recruits MRE11 and NBS1 or ribosylates $B R C A$ )
PARP1 prevents binding of Ku proteins to free DNA ends (first step to start NHEJ) and thus inhibits NHEJ
PARP1 prevents binding of Ku proteins and directs DSBs to this alternative end-joining (MMEJ) repair pathway

C PARP inhibition in SSB and DSB repair

The PARP inhibitor binds to PARP1
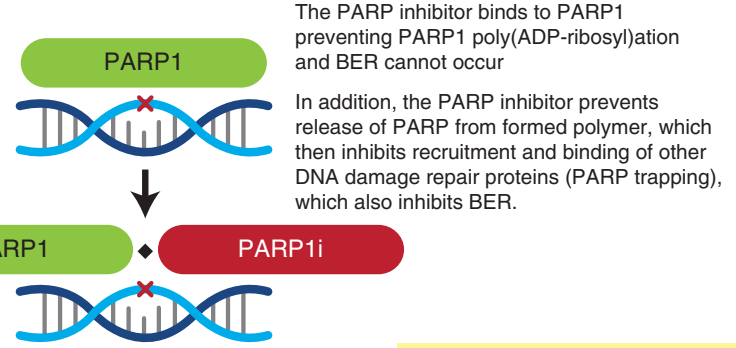

Conversion to DSB $\downarrow$ Mutations in BRCA, RAD51, FA genes, PALB2, etc. lead to HR deficiency and inability to repair DSBs

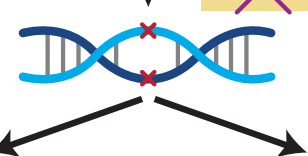

HR
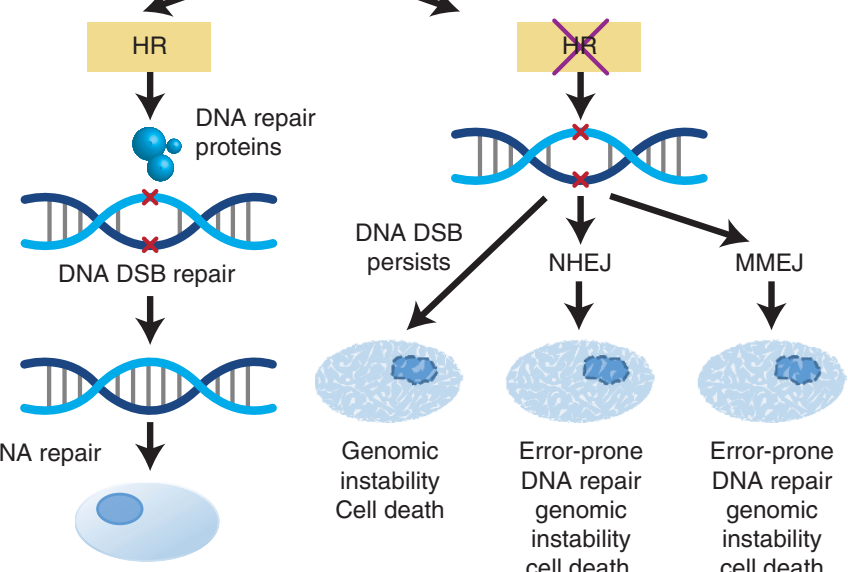

$\begin{array}{lcc}\text { Genomic } & \text { Error-prone } & \text { Error-prone } \\ \text { instability } & \text { DNA repair } & \text { DNA repair } \\ \text { Cell death } & \text { genomic } & \text { genomic } \\ & \text { instability } & \text { instability } \\ & \text { cell death } & \text { cell death }\end{array}$

Figure 1. Role of PARP in DNA repair and main effects of PARP inhibitors. (A) Main DNA repair mechanisms, key pathway components and role of PARP1 for each pathway. (B) DNA single strand break repair by base excision repair. (C) Effect of PARP inhibition on DNA single and double strand break repair. AP, apurinic/apyrimidinic; ATM, ataxia telangiectasia; BER, base excision repair; DNA-PKcs, DNA-dependent protein kinase, catalytic subunit; DSB, double-strand break; FA, Fanconi anemia; FEN1, flap sructure-specific endonuclease 1; HR, homologous recombination; KU70 and KU80, make up the Ku heterodimer; MMEJ, microhomologymediated end joining; MRN, MRE11-RAD50-NBS1 protein complex; NBN, Nibrin; NHEJ, non-homologous end joining; PARP, poly (ADP-ribose) polymerase; PALB2, partner and localiser of BRC; PARPi, PARP inhibitor; RAD51, eukaryote gene of RAD51 protein family; SSB, single-strand break. 
repaired by the base excision repair pathway, are left unresolved. Following duplication of the DNA strand this can lead to a DSB, which under normal circumstances can be repaired by the HR pathway, preserving cell viability. When HR repair is compromised as in BRCAdeficient cells, the DNA DSBs are not repaired (Ashworth, 2008). However, the validity of this premise has been debated, as removal of XRCC1 (a protein acting immediately downstream of PARP1 that is essential for base excision repair) in HR-deficient cells does not result in cell death suggesting that loss of PARP is critical for killing HR-deficient cells, but loss of base excision repair is not (Rouleau et al, 2010; Patel et al, 2011; Curtin, 2014; Scott et al, 2015).

PARP1 trapping. Recent evidence suggests that PARP inhibitors promote cell death by trapping PARP1 on the damaged DNA (Figure 1; Helleday, 2011; Strom et al, 2011; Murai et al, 2012; Horton et al, 2014). Normally, when DNA damage activates PARP1, the resulting $\mathrm{pADPr}$ recruits additional repair proteins, but once repair is initiated, it also diminishes the affinity of PARP1 for DNA, allowing PARP1's dissociation and the subsequent binding of other repair factors (Satoh and Lindahl, 1992; Scott et al, 2015). If PARP1 activity is inhibited such that it cannot synthesise pADPr polymers, it remains bound (trapped) to the damaged DNA, essentially blocking DNA repair (Satoh and Lindahl, 1992). Similarly, PARP inhibitor inactivation of PARP1 activity may consequently trap PARP1 on DNA repair intermediates, obstructing replication forks (Figure 1c; Horton et al, 2014). Therefore, PARP inhibitors may act, in part, as 'poisons' that trap the PARP1 enzyme on DNA. Importantly, PARP trapping may be more cytotoxic than loss of its catalytic activity (Murai et al, 2012). In support of this premise, the PARP catalytic inhibitory activities of the three PARP inhibitors, niraparib, olaparib, and veliparib, do not correlate strongly with respect to cytotoxic and trapping potency; niraparib and olaparib have greater cytotoxic and trapping activity than veliparib (Table 1; Murai et al, 2012). This may be the result of the differences in drug allosteric binding to the $\mathrm{NAD}^{+}$site, with the bulky inhibitors, niraparib and olaparib, possessing greater potency to produce PARP-DNA 'trapped' complexes compared with veliparib (Murai et al, 2012). Preclinical studies have also suggested that differences in the catalytic inhibitory and trapping activities of various PARP inhibitors may explain differences in synergism when combined with selected chemotherapeutic agents (Murai et al, 2012). For example, because temozolomide forms PARP-DNA complexes at SSBs, combining it with PARP inhibitors with higher PARP-trapping properties, such as niraparib or olaparib, may be a more efficacious option than a combination with an agent expressing less potent trapping activity, such as veliparib (Murai et al, 2012). Preclinical studies have also shown that stereospecific PARP trapping is more pronounced for talazoparib when compared to olaparib or rucaparib (Murai et al, 2014). These differences in catalytic and trapping activities may be important when combining PARP inhibitors with chemotherapeutic agents. One example is the observation that talazoparib demonstrates greater cytotoxicity than other PARP inhibitors in combination with the DNA alkylating agents methyl methane sulfonate or temozolomide (Murai et al, 2014; Hopkins et al, 2015).

Defective BRCA1 recruitment. BRCA1 is recruited to damaged DNA via several steps. BRCA1 is recruited through its binding to BARD1, which binds pADPr at the damage site. BRCA1 also binds with $\gamma-\mathrm{H} 2 \mathrm{AX}$ a histone that is modified in response to damaged DNA (De Lorenzo et al, 2013) (Figure 1). If a specific mutation in BRCA1 disrupts the $\gamma$-H2AX interaction, the binding of the BRCA1-BARD1 complex becomes critical for HR. The ability of PARP inhibitors to reduce recruitment of the BARD1-BRCA1 complex to damaged DNA may result in cell death in the setting of a BRCA mutation where the interaction with $\gamma-\mathrm{H} 2 \mathrm{AX}$ is diminished ( $\mathrm{Li}$ and $\mathrm{Yu}, 2013)$. However, this model does not explain PARP inhibitor effects in cells that do not carry mutations in BRCA1, which disrupt BRCA1/ $\gamma$-H2AX complex formation (Scott et al, 2015).

Activation of non-homologous end joining. Another proposed mechanism for PARP inhibitor activity is based on the role of PARP1 in suppression of the microhomology-mediated end joining and error-prone NHEJ repair pathways (Figure 1). Several proteins including Ku70, Ku80, and DNA-PKcs are pADPr binding proteins (Scott et al, 2015). PARP inhibitors prevent the binding of $\mathrm{Ku}$ proteins to free DNA ends (the first step to initate NHEJ) and thus inhibit NHEJ (Lieber, 2010; Patel et al, 2011) resulting in mutations, chromosomal rearrangements, and cell death (Figure 1).

BRCAness: proposed PARP inhibitor efficacy. Certain sporadic OCs display a $B R C A$-like phenotype; therefore, it was proposed that PARP inhibitors may also demonstrate efficacy in such cancers. Data from The Cancer Genome Atlas suggest that approximately $50 \%$ of high-grade serous OC (HGSOC) cases display a BRCA-like phenotype (Cancer Genome Atlas Research Network, 2011). Such BRCAness may occur as a result of epigenetic silencing of $B R C A$ genes or inactivation of other HR-associated genes, including ATM, RAD51, or members of the FANC family of genes (Yap et al, 2011; O'Sullivan et al, 2014). Deficiencies in HR are associated with gene copy number changes that can be described as genomic instability. Recent studies suggest that it may be possible to capture this genomic instability by measuring allelic imbalance or loss of heterozygosity. The burden and pattern of allelic imbalance may distinguish subtypes of OC, and genomic signatures might predict response to treatment with PARP inhibitors (Haluska et al, 2014; Matulonis et al, 2014; Swisher et al, 2014).

\section{CLINICAL APPLICATION}

Multiple PARP inhibitors, including olaparib, veliparib, niraparib, rucaparib, and talazoparib, are currently being evaluated in clinical trials (Table 2). The most common PARP inhibitor chemistry is that of reversible NAD mimetics. The drugs differ in bioavailability, molar equivalence of PARP enzyme inhibition, and PARP trapping capability (Table 1). The loss of DNA repair in the presence of these molecules has led to the evaluation of these drugs as single agents and as potential enhancers of cytotoxic agents that provoke DNA damage, such as alkylating agents and radiation therapy (Lee et al, 2014). Several of these agents have been and are being investigated in patients with $\mathrm{g} B R C A 1 / 2$-associated and sporadic platinum-sensitive and/or platinum-resistant OC (Liu et al, 2014). In addition, PARP inhibitors are being investigated in combination with other targeted agents, such as in PI3-kinase or angiogenesis inhibitors. The VEGF monoclonal antibody $(\mathrm{mAb})$ bevacizumab has been shown to induce hypoxia in the tumour microenvironment which may contribute to genomic instability and in doing so is thought to increase the sensitivity of cells to PARP inhibitors (Bindra et al, 2004, 2005; Chan et al, 2010; Sehouli et al, 2016).

Of note, iniparib, which was originally thought to be a PARP inhibitor, failed to demonstrate clinical activity in a randomised phase III study in patients with BRCA mutation-positive breast cancer. Following further preclinical studies iniparib is no longer classified as a PARP inhibitor as it failed to exhibit characteristic properties of PARP inhibitors. Therefore, results of iniparib studies should have no bearing on clinical decisions regarding PARP inhibitors (Patel et al, 2012).

Olaparib. Olaparib was the first PARP inhibitor to gain US FDA approval, based in-part on data from a single-arm trial that included 137 advanced OC patients with gBRCA mutations who were 
Table 1. PARP inhibitors under development

\begin{tabular}{|c|c|c|c|c|c|c|}
\hline PARP inhibitor & Route & $\begin{array}{c}\text { PARP catalyitic } \\
\text { inhibition }\left(I_{50}\right) \\
\text { (Murai et al, } \\
2012,2014 \text { ) }\end{array}$ & $\begin{array}{l}\text { In vitro } \\
\text { Cytotoxicity } \\
\text { (Murai et al, } \\
2012,2014 \text { ) }\end{array}$ & $\begin{array}{l}\text { In vitro } \\
\text { PARP trapping } \\
\text { (Murai et al, } \\
2012,2014 \text { ) }\end{array}$ & Treatment & Cancer types \\
\hline $\begin{array}{l}\text { Veliparib (ABT-888) } \\
\text { (Abbvie) }\end{array}$ & Oral & $10.5 \mathrm{nmoll}^{-1}$ & + & + & $\begin{array}{l}\text {-Monotherapy } \\
\text {-Combinations with } \\
\text { cytotoxic chemotherapy } \\
\text {-Combinations with } \\
\text { targeted agents } \\
\text {-Combinations with RT }\end{array}$ & $\begin{array}{l}\text {-BRCA1/2MUT + associated } \\
\text { BrCa/OvCa } \\
\text {-BRCA-like tumours, } \\
\text {-Advanced hematologic } \\
\text { malignancies and solid } \\
\text { tumours }\end{array}$ \\
\hline $\begin{array}{l}\text { Talazoparib } \\
\text { (BMN 673) } \\
\text { (Pfizer) }\end{array}$ & Oral & $4 \mathrm{nmoll}^{-1}$ & ++++ & ++++ & -Monotherapy & $\begin{array}{l}\text {-Advanced hematologic } \\
\text { malignancies and solid } \\
\text { tumours }\end{array}$ \\
\hline Rucaparib (Clovis) & Oral & $21 \mathrm{nmoll}^{-1}$ & ++ & ++ & $\begin{array}{l}\text {-Monotherapy } \\
\text {-Combinations } \\
\text { (carboplatin) }\end{array}$ & $\begin{array}{l}\text {-Advanced solid tumours } \\
\text { - Recurrent OvCa, } \\
\text {-BRCA1/2MUT+ associated } \\
\text { BrCa/OvCa }\end{array}$ \\
\hline $\begin{array}{l}\text { Niraparib (MK-4827) } \\
\text { (TesaroBio) }\end{array}$ & Oral & $50.5 \mathrm{nmoll}^{-1}$ & +++ & +++ & $\begin{array}{l}\text {-Monotherapy } \\
\text {-Combinations } \\
\text { (temozolomide) }\end{array}$ & $\begin{array}{l}\text {-Advanced hematologic } \\
\text { malignancies and solid } \\
\text { tumours } \\
\text {-BRCA1/2MUT + associated } \\
\text { and HER2 negative BrCa, } \\
\text {-Maintenance study following } \\
\text { remission in platinum sensitive } \\
\text {-OvCa }\end{array}$ \\
\hline
\end{tabular}

previously treated with three or more lines of chemotherapy. In this study, patients received olaparib $400 \mathrm{mg}$ twice daily; the objective response rate (ORR) was 34\% (46/137), of those, 32\% (44/137) had partial response (PR) and $2 \%(2 / 137)$ demonstrated a complete response (CR). The median duration of response (DoR) was 7.9 months (Domchek et al, 2016). The approval was also based on supportive efficacy outcomes derived from other clinical trials in which olaparib had been previously assessed (Fong et al, 2009, 2010; Audeh et al, 2010; Gelmon et al, 2011; Kaye et al, 2012).

In an initial phase I trial, antitumour activity of olaparib was observed in patients with gBRCA-mutated advanced OC and the maximum tolerated dose (MTD) was determined to be $400 \mathrm{mg}$ twice daily (Fong et al, 2009). A phase II trial confirmed durable antitumour responses with olaparib in advanced OC patients with BRCA1/2 mutations. The ORR was $33 \%$ for 33 patients who received olaparib $400 \mathrm{mg}$ twice daily and $13 \%$ for 24 patients who received $100 \mathrm{mg}$ twice daily (Audeh et al, 2010). In an expanded cohort of the phase I trial, patients with ovarian, primary peritoneal, or fallopian tube cancer were treated with $200 \mathrm{mg}$ olaparib twice daily and 20 of 50 patients(40\%) had an objective and/or tumour marker response. Median DoR was 7 months. The clinical benefit rate correlated with platinum sensitivity (69\% in platinum-sensitive, $46 \%$ in platinum-resistant, and $23 \%$ in platinum-refractory disease) (Fong et al, 2010).

A phase II open-label, randomised, controlled trial compared olaparib and pegylated liposomal doxorubicin (PLD) in patients with gBRCA-mutated advanced OC; olaparib demonstrated efficacy consistent with previous studies. No significant differences were observed between treatments in overall response rate (ORR) or progression-free survival (PFS). The ORR was $25 \%, 31 \%$, and $18 \%$ for olaparib $200 \mathrm{mg}$ twice daily, olaparib $400 \mathrm{mg}$ twice daily, and PLD, respectively. Median PFS was 6.5 months for olaparib $200 \mathrm{mg}$ twice daily, 8.8 months for olaparib $400 \mathrm{mg}$ twice daily, and 7.1 months for PLD (Kaye et al, 2012).

In addition, a phase II open-label, nonrandomised, single-arm study was the first to demonstrate antitumour activity of a PARP inhibitor in sporadic HGSOC. Confirmed PRs were seen in $24 \%$ $(11 / 46)$ of patients without gBRCA mutations and in $41 \%(7 / 17)$ of patients with gBRCA mutations (Gelmon et al, 2011).

A large, randomised phase II maintenance therapy trial of olaparib demonstrated efficacy among patients with platinumsensitive (CR or PR), relapsed OC (Ledermann et al, 2012, 2014). Results of this randomised, double-blind, placebo-controlled study revealed a significant improvement in PFS in patients treated with olaparib maintenance therapy $400 \mathrm{mg}$ twice daily $(n=136)$ compared with placebo $(n=129 ; 8.4$ vs 4.8 months for placebo, hazard ratio $=0.35$ (95\% CI, 0.25-0.49); $P<0.001$; Ledermann et al, 2012). Subset analyses showed that among patients with a germline or tumour BRCA mutation median PFS was significantly longer in the olaparib group $(n=74)$ than in the placebo group $(n=62 ; 11.2$ vs 4.3 months, hazard ratio $=0.18$ (95\% CI, 0.10 $0.31) ; P<0.0001)$. Significant improvements in PFS were also noted for patients without a BRCA mutation $(n=57)$ compared with placebo $(n=61)$; however, the difference was less robust (7.4 
Table 2. Most common AEs (any grade and grade $\geqslant 3$ ) with olaparib treatment based on data from 2 large olaparib clinical trials. Shown are any grade AEs reported in at least $15 \%$ of patients or grade $\geqslant 3$ AEs reported in at least $5 \%$ of patients

\begin{tabular}{|c|c|c|c|c|c|c|}
\hline & \multicolumn{2}{|c|}{ Kaufman et al (2015) } & \multicolumn{4}{|c|}{ Ledermann et al (2012) } \\
\hline & \multicolumn{2}{|c|}{ Olaparib $N=193$} & \multicolumn{2}{|c|}{ Olaparib $N=136$} & \multicolumn{2}{|c|}{ Placebo $\mathbf{N}=128$} \\
\hline & $\begin{array}{c}\text { Any grade } \\
\text { number (\%) }\end{array}$ & $\begin{array}{c}\text { Grade } \geqslant 3 \\
\text { number }(\%)\end{array}$ & $\begin{array}{c}\text { Any grade } \\
\text { number (\%) }\end{array}$ & $\begin{array}{c}\text { Grade } \geqslant 3 \\
\text { number }(\%)\end{array}$ & $\begin{array}{c}\text { Any grade } \\
\text { number (\%) }\end{array}$ & $\begin{array}{c}\text { Grade } \geqslant 3 \\
\text { number }(\%)\end{array}$ \\
\hline Fatigue & $116(60.1)$ & $12(6.2)$ & $66(48.5)$ & $9(6.6)$ & $48(37.5)$ & $4(3.1)^{a}$ \\
\hline Nausea & $119(61.7)$ & $1(0.5)$ & $93(68.4)$ & $3(2.2)$ & $45(35.2)$ & $0(0)$ \\
\hline Vomiting & 75 (38.9) & $5(2.6)$ & $43(31.6)$ & $3(2.2)$ & $18(14.1)$ & $1(0.8)$ \\
\hline Anemia & $62(32.1)$ & $36(18.7)$ & $23(16.9)$ & $7(5.1)$ & $6(4.7)$ & $1(0.8)$ \\
\hline Diarrhea & $56(29.0)$ & $3(1.6)$ & $31(22.8)$ & $3(2.2)$ & $29(22.7)$ & $3(2.3)$ \\
\hline Abdominal pain & $58(30.1)$ & $14(7.3)$ & $24(17.6)$ & $2(1.5)$ & $33(25.8)$ & $4(3.1)$ \\
\hline Decreased appetite & $36(18.7)$ & $1(0.5)$ & $25(18.4)$ & $0(0)$ & $17(13.3)$ & $0(0)$ \\
\hline Dyspepsia & $38(19.7)$ & $0(0)$ & $22(16.2)$ & $0(0)$ & $11(8.6)$ & $0(0)$ \\
\hline Headache & $32(16.6)$ & $0(0)$ & $25(18.4)$ & $0(0)$ & $15(11.7)$ & $1(0.8)$ \\
\hline Dysgeusia & $39(20.2)$ & $0(0)$ & $19(14.0)$ & $0(0)$ & $8(6.3)$ & $0(0)$ \\
\hline \multicolumn{7}{|c|}{$\begin{array}{l}\text { ane patient in the placebo group inadvertently received olaparib at a dose of } 400 \mathrm{mg} \text { twice daily for approximately } 2 \text { weeks. The exact dates and duration are unknown. It is not known } \\
\text { whether the patient was receiving olaparib or placebo when the adverse event (AE) occurred. This AE was counted in the safety analysis for placebo, but the possibility that it was attributable to } \\
\text { olaparib cannot be excluded. }\end{array}$} \\
\hline
\end{tabular}

vs 5.5 months, hazard ratio $=0.54 \quad(95 \%$ CI, $0.34-0.85)$; $P=0.0075)$. At a second interim analysis of OS (58\% maturity), OS for patients with germline or tumour BRCA mutations did not significantly differ between the groups (hazard ratio $=0.88$ (95\% CI, 0.64-1.21); $P=0.44$; Ledermann et al, 2014). In an updated analysis olaparib significantly improved times to first and second subsequent therapy (Ledermann et al, 2016). Moreover, maintenance olaparib gave patients a survival advantage, however, analyses suggest that these results may have been driven by the BRCAm group (5-year survival was $29.2 \%$ and $20.4 \%$ in the olaparib and placebo arms, respectively, and $36.9 \%$ and $24.3 \%$ in BRCAm patients; Ledermann et al, 2016).

Although most studies have assessed olaparib in patients with platinum-sensitive OC, results of the recent single-arm, phase II study showed encouraging results in patients with platinumresistant OC (Kaufman et al, 2015). The study included 298 patients with confirmed germline BRCA1 or BRCA2 mutation and advanced solid tumours. Among the cohort of 193 patients with platinum-resistant OC, 31\% (60/193) achieved a response and $40 \%$ $(78 / 193)$ had stable disease for $\geqslant 8$ weeks. Median PFS and OS were 7 months and 16.6 months, respectively.

Across trials, olaparib has shown a consistent adverse event (AE) profile. The most common treatment-related AEs were fatigue, gastrointestinal symptoms (nausea, vomiting, diarrhea), and anemia, most of which were grade $1 / 2$. The reported major toxicities of the two largest clinical trials with olaparib are shown in Table 2 (Ledermann et al, 2012; Kaufman et al, 2015). Although most AEs were mild-to-moderate, consideration must be given to the development of serious, potentially fatal conditions, such as myelodysplastic syndrome/acute myeloid leukemia (MDS/AML) and pneumonitis, which have occurred rarely with olaparib treatment. MDS/AML was confirmed in 2\% (3/136) of treated patients in a randomised placebo-controlled trial and in $2 \%(6 / 298)$ of treated patients in a single-arm monotherapy trial (Lynparza prescribing information, 2014). Across all reported olaparib studies, MDS/AML was reported in <1\% $(22 / 2,618)$ of patients and pneumonitis, including fatal cases, occurred in $<1 \%$ of patients. MDS/AML likely result from PARP inhibitor-related disruption in DNA repair, as altered DNA repair mechanisms can lead to the development of genomic instability that in itself may promote carcinogenesis (Bhatia, 2013).
Additional phase III maintenance trials for olaparib following chemotherapy are underway (Table 3). These trials use the new tablet formulation of olaparib developed to facilitate olaparib dosing. Current approval of olaparib is based on completed clinical studies where the dose of olaparib was $400 \mathrm{mg}$ twice daily using a capsule formulation; each capsule was $50 \mathrm{mg}$, equaling a total pill count of 16 capsules per day. Clinical studies have now been completed which compare the bioavailability and match the efficacy and tolerability of the tablet to that of the capsule (Mateo et al, 2016). As a result, the $300-\mathrm{mg}$ tablet formulation $(2 \times 150 \mathrm{mg}$ tablets twice daily) was chosen as the most suitable dose for all phase III studies. The phase III SOLO1 study, conducted in collaboration with the Gynecologic Oncology Group, will provide information on the role of maintenance olaparib after frontline chemotherapy for OC patients with gBRCA mutations. SOLO2, in collaboration with the European Network of Gynaecological Oncological Trial Groups, will evaluate the role of maintenance olaparib after $\geqslant 2$ lines of chemotherapy for OC patients with gBRCA mutations. Both trials are randomised, double-blind, placebo-controlled studies that utilise the new tablet formulation of olaparib at a dose of $300 \mathrm{mg}$ twice daily (Moore et al, 2014). In addition, SOLO3 is a randomised, phase III trial in patients with $\mathrm{g} B R C A$ mutated, recurrent $\mathrm{OC}$ in which single-agent olaparib will be compared with standard-of-care chemotherapy in patients who failed $\geqslant 2$ lines of prior chemotherapy for recurrent disease (Table 3).

Olaparib is also under investigation in combination with chemotherapeutic agents. In a randomised, open-label, phase II study, patients with platinum-sensitive, recurrent OC received either olaparib (200 mg twice daily, days 1-10 of each 21-day treatment cycle) plus paclitaxel $\left(175 \mathrm{mg} \mathrm{m}^{-2}\right.$, intravenously, day 1 of each cycle) and carboplatin (area under the curve (AUC) 4, according to the Calvert formula, intravenously, day 1 of each cycle) followed by olaparib monotherapy ( $400 \mathrm{mg}$ twice daily, continuously), or paclitaxel ( $175 \mathrm{mg} \mathrm{m}^{-2}$, day 1 of each cycle) and carboplatin (AUC 6, day 1 of each cycle) followed by no further treatment in the maintenance phase. PFS was significantly improved for the olaparib plus paclitaxel/carboplatin group versus chemotherapy alone (12.2 vs 9.6 months, respectively (hazard ratio $=0.51,95 \% \mathrm{CI}, 0.34-0.77 ; P=0.0012)$ ); the toxicity profile for the olaparib group was manageable (Oza et al, 2015). In a phase 


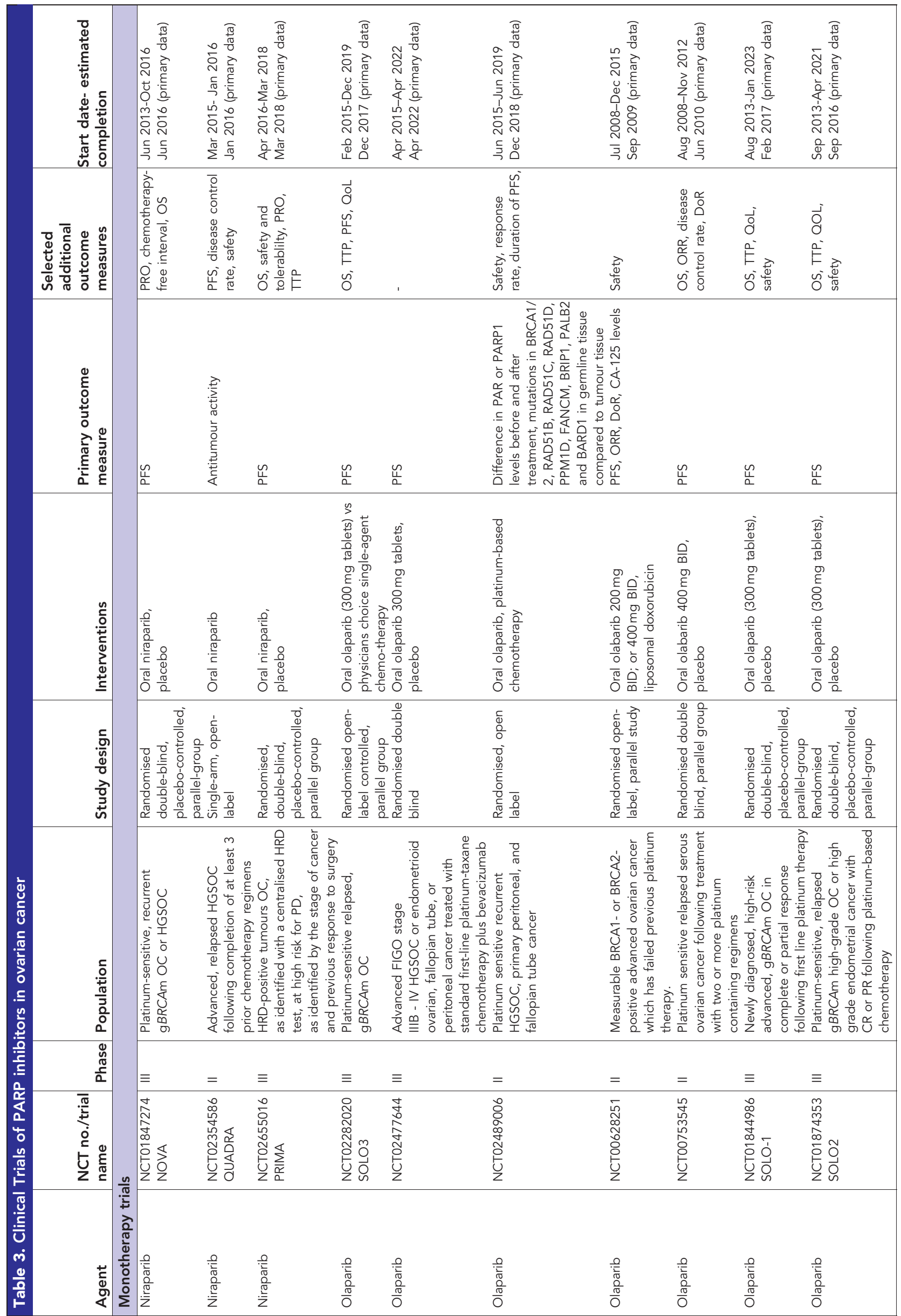




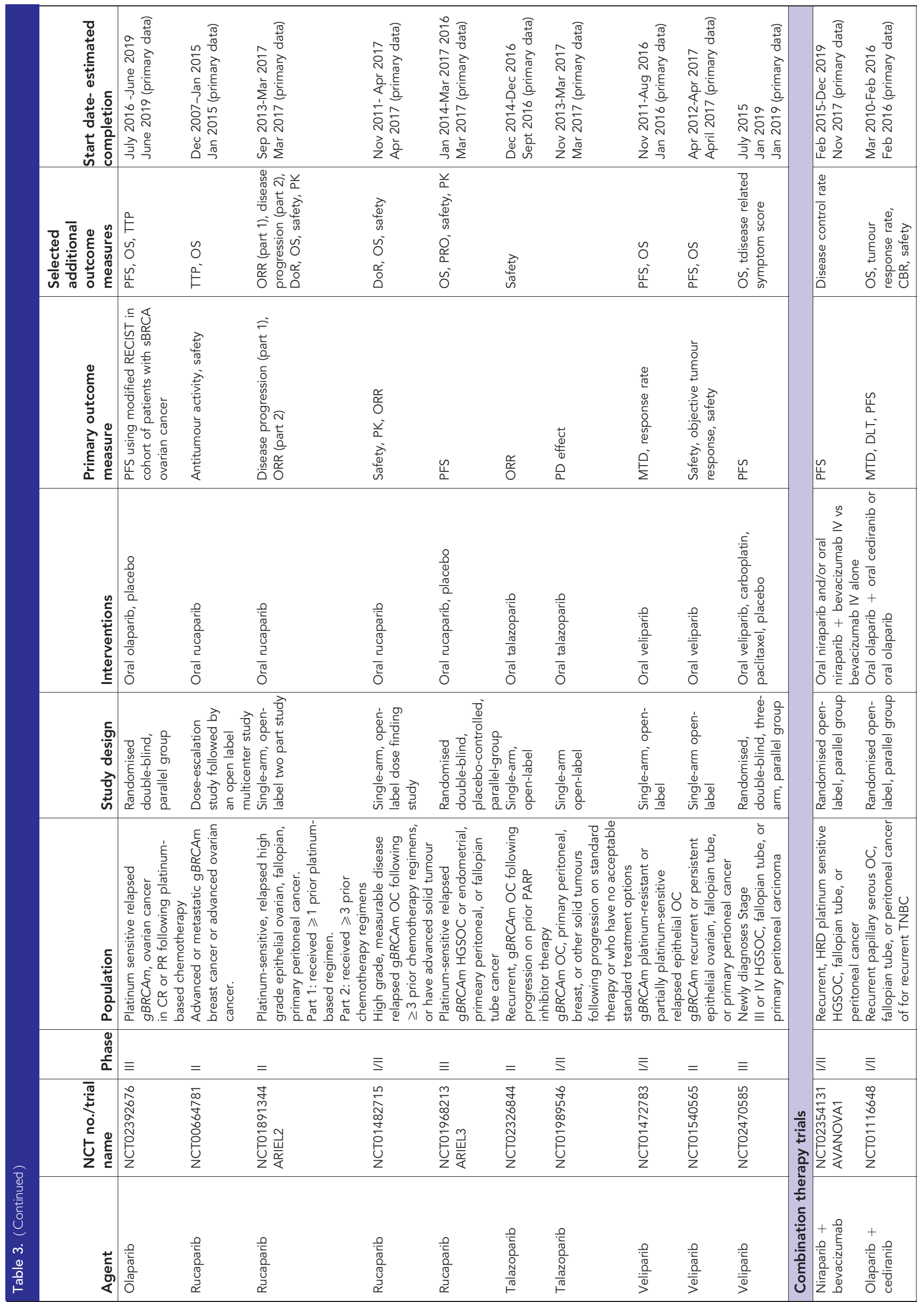




\begin{tabular}{|c|c|c|c|c|c|c|c|c|c|c|c|c|}
\hline 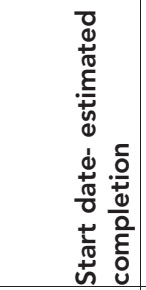 & 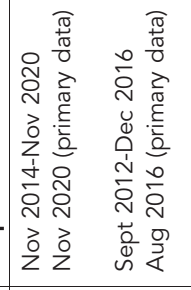 & 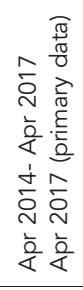 & 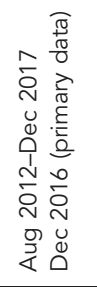 & 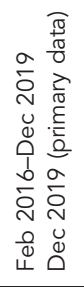 & 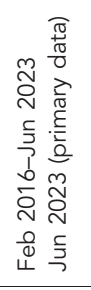 & 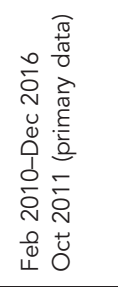 & 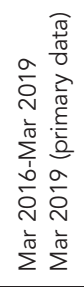 & 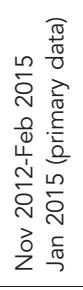 & 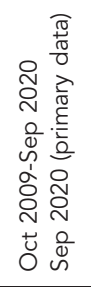 & 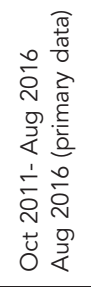 & 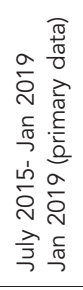 & 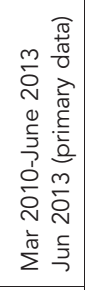 \\
\hline 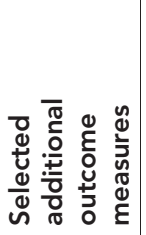 & 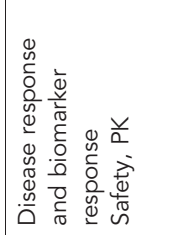 & $\begin{array}{l}\stackrel{\vec{U}}{\vec{x}} \\
\stackrel{\overrightarrow{0}}{\vdash}\end{array}$ & 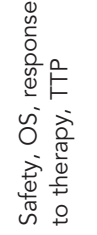 & 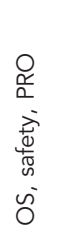 & 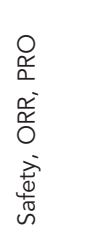 & 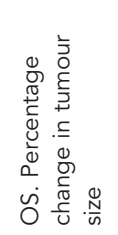 & 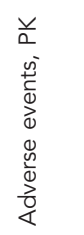 & 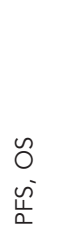 & 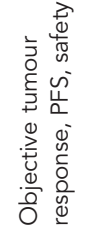 & 产 & 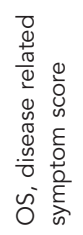 & 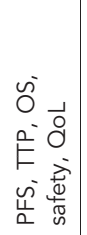 \\
\hline
\end{tabular}

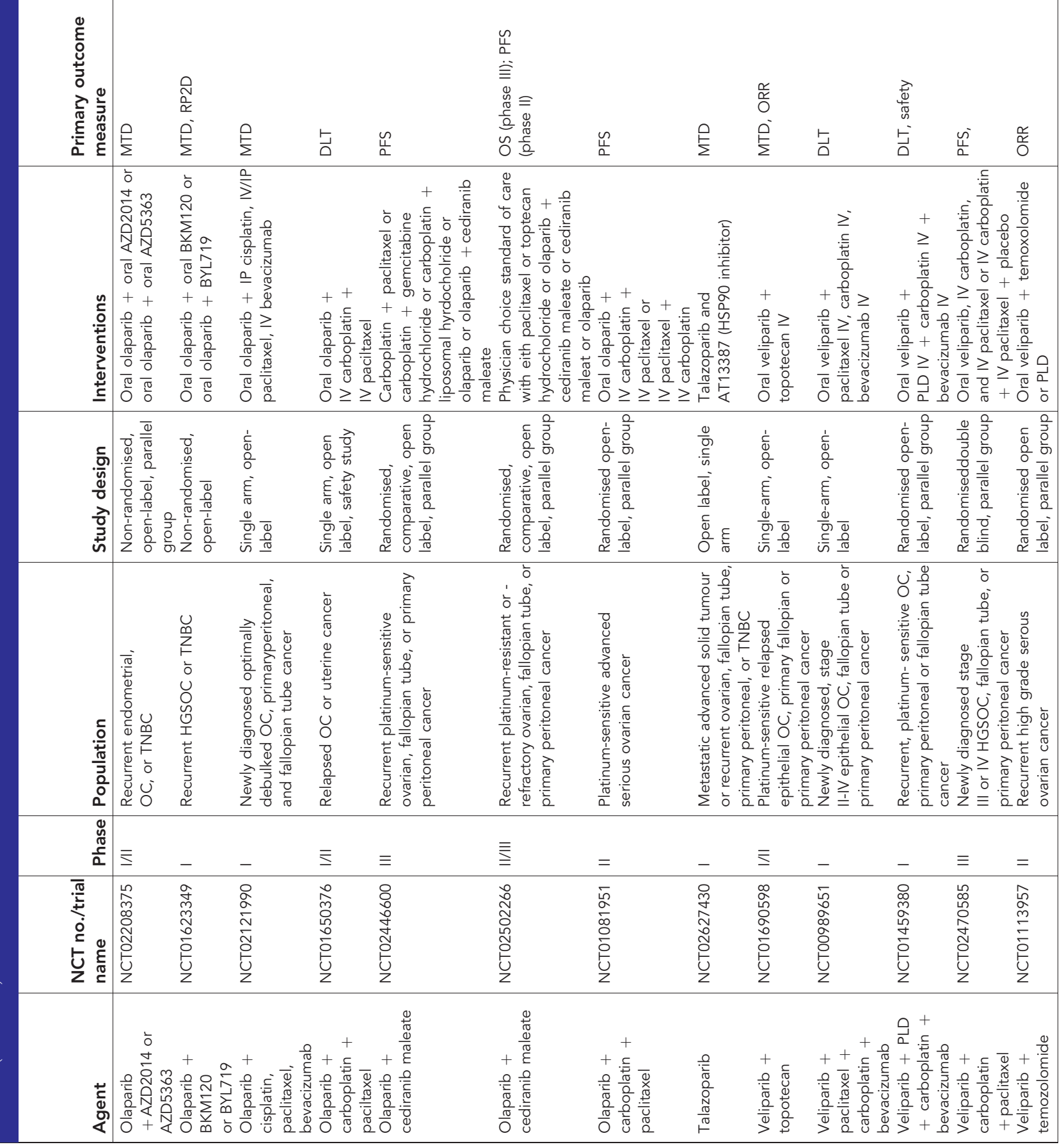




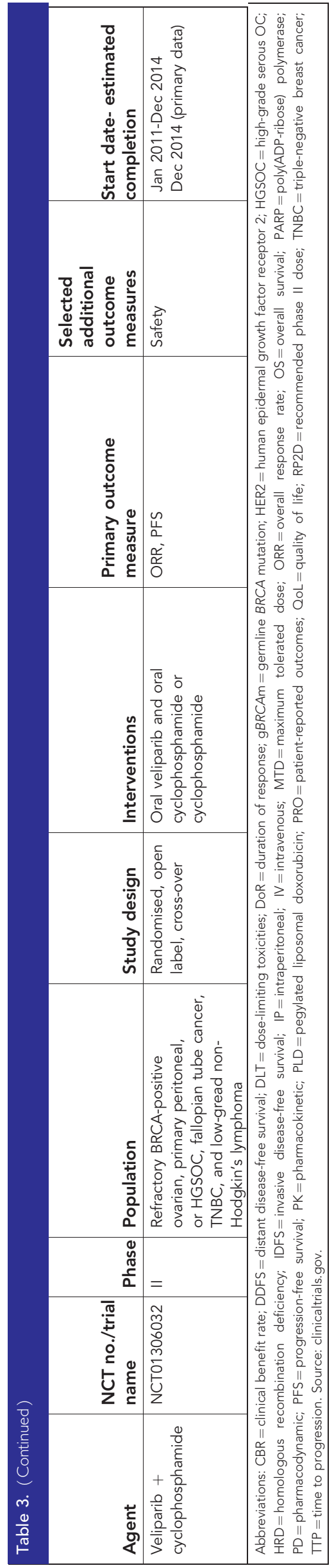

I, open-label, dose-finding study, olaparib (100, 200, or $400 \mathrm{mg}$ twice daily) was administered intermittently (7 days) or continuously (28-day treatment cycle) in combination with liposomal doxorubicin ( $40 \mathrm{mg} \mathrm{m}^{-2}$ every 28 days). The MTD was not reached with olaparib $400 \mathrm{mg}$ twice daily. The combination was active and generally well-tolerated (Del Conte et al, 2014).

Pooled data from the previously mentioned six olaparib trials (two Phase I trials and four Phase II studies; Fong et al, 2009, 2010; Audeh et al, 2010; Gelmon et al, 2011; Kaye et al, 2012; Mateo et al, 2013; Kaufman et al, 2015) that recruited women with relapsed ovarian, fallopian tube, or peritoneal cancer were used to explore the activity of olaparib in relation to the number of prior treatment lines in patients with $g B R C A m$ ovarian cancer (Matulonis et al, 2016). All patients received $400 \mathrm{mg}$ of olaparib twice per day. In the pooled population with measurable disease at baseline $(n=273)$, the ORR was $36 \%$ with a 7.4 month median DoR. For patients who had received $\geqslant 3$ lines of prior chemotherapy $(n=205)$, the ORR was $31 \%$ and median DoR was 7.8 months. The ORR declined as the number of lines increased from $50 \%$ for patients who had received one prior regimen to $24 \%$ for patients who had received $\geqslant 6$ prior regimens. Grade $\geqslant 3$ adverse events were reported in $50 \%$ of the pooled population and $54 \%$ of the population who had $\geqslant 3$ lines of prior chemotherapy. The findings of the study indicated that olaparib was associated with durable response in patients with relapsed gBRCA-mutated ovarian cancer and who had been administered $\geqslant 3$ lines of prior chemotherapy.

Combination studies with a number of other agents are also being assessed. Olaparib was studied in combination with the antiangiogenic multikinase inhibitor, cediranib. The rationale behind this combination is based on the observation that vascular endothelial growth factor receptor (VEGFR) inhibition may lead to increased DNA damage through downregulation of DNA repair proteins, including ERCC1 and XRCC1 (Yadav et al, 2011). Stemming from supportive preclinical data (Pyriochou et al, 2008), a phase II trial of olaparib in combination with the VEGF multikinase inhibitor, cediranib, was recently completed (Liu et al, 2014). Patients received 30-mg cediranib daily and olaparib $200 \mathrm{mg}$ twice daily. Median PFS was 17.7 months for women treated with cediranib plus olaparib $(n=44)$ compared with 9.0 months for those treated with olaparib monotherapy $(n=46$; hazard ratio $=0.42 ; P=0.005)$. OS data were not mature; OS at 24 months was $81 \%(95 \% \mathrm{CI}, 60-91)$ in the combination group compared with $65 \%$ (95\% CI, 42-81) in the olaparib-monotherapy group. Treatment-related AEs were more common in patients treated with cediranib plus olaparib than with monotherapy. These included grade 1/2 AEs of hypertension (17 vs 0 patients, respectively), diarrhea (31 vs 1), fatigue (26 vs 21), headache (17 vs 4), hypothyroidism (7 vs 1), and decrease in white blood cell (5 vs 4) and platelet counts (6 vs 3), as well as grade 3/4 AEs including fatigue (12 vs 5 patients), diarrhea (10 vs 0$)$, and hypertension (18 vs 0; Liu et al, 2014).

Most recently, results of phase I studies of olaparib in combination with the PI3K inhibitor BKM120 and the AKT inhibitor AZD5363 have been reported with evidence of activity in OC (Matulonis et al, 2015; Michalarea et al, 2015). The rationale for these studies was based on preclinical data in breast cancer models showing that inhibition of the PI3/AKT pathway can result in BRCA1/2 downregulation, HR impairment, and sensitivity to PARP inhibition (Ibrahim et al, 2012; Juvekar et al, 2012).

Veliparib. Veliparib has been evaluated in phase I studies as single agent and in combination with chemotherapeutic agents. Advanced-phase trials are currently ongoing. A phase II study is investigating veliparib monotherapy in patients with $\mathrm{g} B R C A$ mutations and recurrent OC (Table 3). Preliminary results 
reported an ORR of 26\% (13/50 patients). Responses were observed in both platinum-sensitive and platinum-resistant patients and median PFS was 8.1 months. Gastrointestinal symptoms, fatigue, and anemia were the most common AEs (Coleman et al, 2015).

A phase I trial of veliparib with cyclophosphamide observed antitumour responses in patients $(N=35)$ with OC, breast cancer, urothelial or lymphoid malignancies. The MTD was found to be veliparib $60 \mathrm{mg}$ once daily plus cyclophosphamide $50 \mathrm{mg}$ once daily (Kummar et al, 2012). Seven patients had PR; an additional 6 patients had disease stabilisation for at least six cycles. Based on preclinical data supporting the interaction between inihibition of PARP and the VEGF signalling pathway (Pyriochou et al, 2008; Yadav et al, 2011), a phase I study was conducted to evaluate veliparib in combination with a platinum/taxane regimen plus bevacizumab in epithelial ovarian fallopian or primary peritoneal cancer $(N=189)$ (Bell-McGuinn et al, 2015). An ongoing GOG phase III study is currently evaluating carboplatin/paclitaxel with or without concurrent and continuation maintenance veliparib in patients with previously untreated stages III or IV high-grade serous epithelial ovarian, fallopian, or primary peritoneal cancer (NCT02470585).

Niraparib. Niraparib is under investigation in patients with and without BRCA-mutated cancer (Sandhu et al, 2013). In a phase I/Ib study, 100 patients with advanced solid tumours were enrolled and $300 \mathrm{mg}$ daily was established as the MTD. A PR was confirmed in 8 of $20(40 \%)$ BRCA-mutation carriers with OC or primary peritoneal cancer, with more responses in platinum-sensitive (50\%) than platinum-resistant (33\%) disease. Durable PRs were also observed in sporadic HGSOC in 2 of 3 patients with platinumsensitive disease and 3 of 19 (16\%) patients with platinum-resistant disease. Fatigue, GI symptoms, and hematologic toxicity (anemia, thrombocytopenia, and neutropenia) were the most commonly reported drug-related toxicities. Niraparib was also evaluated in the recently completed phase III maintenance study, NOVA (NCT01847274), in patients with recurrent platinum sensitive HGSOC (Table 3). The NOVA trial successfully achieved its primary endpoint of PFS in patients with germline BRCA mutations (21.0 vs 5.5 months HR $0.27, P<0.0001)$ and in patients who were not germline BRCA mutation carriers but whose tumours were determined to be HR-deficiency positive (12.9 vs 3.8 months HR 0.38, $P<0.0001)$. http://www.globenewswire.com/NewsRoom/ AttachmentNg/6ea284b2-a663-4aeb-96c1-22ac847b460f. A phase I/II study is exploring the efficacy of niraparib and/or the combination of niraparib plus bevacizumab compared with bevacizumab alone (Table 3). In addition, the QUADRA (NCT02354586) phase II study is evaluating the safety and efficacy of niraparib in patients who have received at least three previous chemotherapy regimens (Table 3). Finally, the PRIMA study (NCT02655016) is assessing the efficacy of niraparib maintenance treatment following first-line platinum-based chemotherapy in patients with advanced primary ovarian cancer that demonstrates HR DNA repair deficiency.

Rucaparib. Rucaparib has demonstrated favorable preclinical and clinical activity in patients with gBRCA-mutated OC and sporadic, platinum-sensitive OC. A phase I study of rucaparib in patients with advanced solid tumours including gBRCA-mutated ovarian, breast, and pancreatic cancer determined the recommended dose to be $600 \mathrm{mg}$ twice daily based on maximum exposure, manageable toxicity and promising clinical activity (Kristeleit et al, 2014; Shapiro et al, 2013). Durable antitumour responses were observed in a subgroup of platinum-sensitive and platinum-resistant ovarian and primary peritoneal cancer patients. Of 14 patients with a gBRCA mutation, 13 had CR, PR, or stable disease at 12 weeks (Kristeleit et al, 2014). Part 2b of the original dose-finding study (Study 10, NCT01482715) is investigating the efficacy of rucaparib
$600 \mathrm{mg}$ twice daily in heavily pre-treated high-grade serous, BRCAm OC (Drew et al, 2016).

Next to gBRCA1/2 mutations, there are other possible causes of deficient DSB repair that may likewise be associated with responsiveness to PARP inhibitor. Both Foundation Medicine and Myriad Genetics are aiming to identify a genomic signature for BRCA-like OCs. Myriad Genetics has selected a combination of three slightly variable algorithms that are indicative of defective DNA DSB repair in cancer cells and will soon be incorporating the MyChoice HR deficiency assay into ovarian cancer clinical trials (Timms et al, 2014, 2015). Foundation Medicine has partnered with Clovis, who is conducting the phase II and phase III rucaparib trials, ARIEL2 and ARIEL3, in platinum-sensitive, recurrent OC, to prospectively validate an HR deficiency score in the tumours of patients using a next generation DNA sequencing test which determines the degree of loss of heterozygosity $(\mathrm{LOH})$ as a marker of genomic instability for predicting response to rucaparib (Swisher et al, 2014). Preliminary data from 135 patients using a prespecified genomic LOH cut-off have shown response to rucaparib in patients with BRCA mutations (ORR 69\%) and in patients with a $B R C A$-like $\mathrm{LOH}$ high signature (ORR 39\%), which is in contrast to patients without a BRCA mutation or without a BRCA-like signature (ORR 11\%) (McNeish et al, 2015). Refinement of the genomic LOH cutoff improves selection of patients with a BRCA-like LOH high signature more likely to benefit from rucaparib. Updated data from 204 patients using the refined cut off have shown response to rucaparib in patients with BRCA mutations (ORR 80\%) and in patients with a BRCA-like LOH high signature (ORR 39\%), which is in contrast to patients without a BRCA mutation or without a BRCA-like signature (ORR 14\%) (Coleman et al, 2016).

The main treatment-related AEs for rucaparib, most of which were of grade $1 / 2$ severity, have been nausea, vomiting, fatigue, elevated aspartate aminotransferase/alanine aminotransferase, dysgeusia, decreased appetite, anemia, and constipation. Full results of the ARIEL2 trial will inform the pivotal phase III maintenance trial, ARIEL3. ARIEL3 has enrolled subjects and will evaluate rucaparib in patients with platinum-sensitive relapsed ovarian cancer. ARIEL3, will also prospectively validate the predictive power of an HR deficiency assay/score in patients with platinum sensitive ovarian cancer (Table 3) (Swisher et al, 2013).

Talazoparib. Talazoparib, formerly known as BMN673, is an oral PARP inhibitor that is under investigation in patients with advanced or recurrent solid tumours (Shen et al, 2013). In preclinical experiments, talazoparib exhibited selective antitumour cytotoxicity at much lower concentrations than olaparib, rucaparib, and veliparib (Table 1; Shen et al, 2013). Preclinical studies have shown that talazoparib, olaparib, rucaparib, and veliparib inhibit PARP catalytic activity similarly; however, talazoparib is more potent at trapping PARP-DNA complexes (Table 1; Shen et al, 2013). Whether the observed increased preclinical potency translates into improved clinical efficacy will need to be shown in clinical studies. A phase I dose-escalation trial determined the MTD of talazoparib to be $1000 \mu \mathrm{g}$ once daily and revealed promising clinical activity. Eleven of 17 patients with gBRCAassociated OC or primary peritoneal cancer had an objective response to talazoparib (De Bono et al, 2013). In a phase I dose escalation study, patients with advanced malignancies, including OC, were treated with talazoparib plus temozolomide chemotherapy. The results demonstrated efficacy and established an MTD using the standard dose of the PARP inhibitor in combination with a reduced dose of the sensitising chemotherapeutic agent (Wainberg et al, 2015, 2016). Although nearly all of the previously mentioned PARP inhibitors (olaparib, velaparib, niraparib) have been combined with chemotherapeutic agents in early phase I clinical trials, the majority of these early combination studies had 
to be closed prematurely due to increased toxicities or the PARP inhibitor doses needed to be reduced to subtherapeutic dose levels. Of note, in all of these earlier studies the chemotherapy doses were given at or near standard dosing levels and the PARP inhibitor concentrations were gradually increased. In contrast, in the present phase I trial that combined talazoparib with temozolomide, the PARP inhibitor dose was kept high from the onset at a dose with proven single agent activity, and the temozolomide dose was started at a low dose and carefully escalated until an MTD was reached. Based on promising clinical activity seen in the ovarian cancer patients, talazoparib will now be further studied either alone or in combination with temozolomide in patients with recurrent HR-deficient ovarian cancer that has progressed after/or failed prior PARP inhibitor treatment or have not yet been exposed to a PARP inhibitor. This trial will provide us with valuable insights as to whether talazoparib, which has unique PARP trapping capability, will have activity as a second line PARP-inhibitor treatment either as single agent or in combination with low dose chemotherapy.

\section{CLINICAL CHALLENGES}

The presence of a gBRCA mutations appears to be positively correlated with increased survival and responsiveness to chemotherapy (Chetrit et al, 2008; Alsop et al, 2012; Bolton et al, 2012). Because of this, it is expected that patients with $\mathrm{gBRCA}$ associated OC will be exposed to multiple lines of various chemotherapeutic agents during their treatment. Therefore, treatment-free intervals may be of particular importance to this patient population, as they allow adequate recovery from cumulative adverse reactions in preparation for additional treatment regimens. Future studies to assess survival and quality of life are needed to clarify whether the optimal treatment strategy will be treatment at disease recurrence or use of PARP inhibitors as maintenance therapy following response to a platinum-based chemotherapy.

Despite durable antitumour activity reported in patients with $\mathrm{g} B R C A$ mutations to date, the lack of validated biomarkers to predict patients with sporadic OC who may respond to PARP inhibitors remains an important clinical challenge. The attempt to capture genomic instability by identification of 'genomic scarring' or BRCAness (identifying tumours that share molecular features of BRCA mutant tumours) may be accomplished by determining the overall degree of allelic imbalance (loss of heterozygosity; Abkevich et al, 2012), telomeric specific allelic imbalance (Birkbak et al, 2012), and/or large-scale transitions in tumour DNA (Popova et al, 2012). As mentioned above, the approach being pursued by Foundation Medicine and Myriad Genetics is to assess patterns of increased genomic instability as biomarkers for defective HR DNA repair. The resulting genomic signature may indicate an HR deficiency sufficient to predict patients whose cancers are more likely to respond to PARP-inhibitor therapy. However, further studies, both preclinical and clinical, will be needed to define and validate algorithms and cut-offs that are currently being developed to predict response to a PARP inhibitor in ovarian cancer.

Inherent or acquired resistance to PARP-inhibitor therapy also confers a significant clinical challenge. A potential mechanism of acquired resistance to PARP inhibition is the restoration of normal BRCA1/2 protein function by secondary intragenic mutations (Konstantinopoulos et al, 2015). This can occur by mutations that cancel the frameshift of the original mutation and restore an open reading frame or by a genetic reversion of the original mutation resulting in the expression of a functional protein (Edwards et al, 2008; Konstantinopoulos et al, 2015). The actual clinical relevance of secondary mutations that restore BRCA function is, however, currently a matter of debate and requires further study. A retrospective study was conducted in a cohort of 89 patients with relapsed epithelial ovarian cancer and gBRCA 1/2 mutations who demonstrated disease progression on olaparib $200 \mathrm{mg}$ twicedaily and subsequently retreated with platinum-based chemotherapy. Secondary BRCA1/2 mutations were not detected in 6 of the patients with evidence of disease progression, suggesting that other mechanisms may play a role in PARP inhibitor resistance. (Ang et al, 2013). Somatic mutations of TP53BP1, which encodes p53BP1, might also result in partial restoration of HR and DNA repair (Jaspers et al, 2013). In addition, increased drug efflux, mediated by MDR1, might limit exposure of the cancer cells to the effects of a PARP inhibitor (Rottenberg et al, 2008). Importantly, evidence suggests a lack of significant clinical cross-resistance between PARP inhibition and platinum-based chemotherapy, which has important implications for sequencing therapy (Ang et al, 2013).

Long term safety issues are a significant concern, especially if PARP inhibitors are adopted in the frontline treatment of OC. PARP inhibitors, as single-agent therapy, are associated with predominantly mild-to-moderate (grade 1/2) toxicities; however, rarer, more severe toxicities demand special consideration in an adjuvant setting. A small number of cases of MDS/AML or severe pneumonitis have been reported after olaparib therapy, with an overall incidence of $<1 \%$ for each toxicity across all reported studies (Lynparza prescribing information, 2014). However, most of these patients had previously received multiple lines of DNAdamaging, platinum-containing chemotherapies, which may have contributed to these AEs. Future studies will need to capture these AEs, especially in the adjuvant setting.

Although the importance of $\mathrm{gBRCA} 1 / 2$ mutations in managing women with ovarian cancer is well understood, the number of patients who are currently being tested for germline mutations is still limited (Schmid and Oehler, 2014). More widespread genetic testing of patients diagnosed with ovarian cancer including the adoption of multi-gene panels (that capture rare germline mutations in high risk genes next to $B R C A 1 / 2$ mutations) will provide clinicians valuable additional stratification tools to help integrate PARP inhibitors into the treatment of all patients diagnosed with familial ovarian cancer. Moreover, the development of assays that capture deficiencies in HR will extend these advances to a larger group of patients diagnosed with sporadic ovarian cancer.

Finally, cost considerations are a further challenge relevant to PARP inhibitors. Cost-effectiveness studies are needed that take quality of life assessments into consideration to allow a comprehensive value-based assessment of PARP inhibitors in ovarian cancer care. (Sfakianos and Havrilesky, 2011).

\section{FUTURE DIRECTIONS}

Future development of PARP inhibitors will need further clinical studies to better understand: (a) when and how to sequence therapy, (b) which combination treatment strategies potentiate PARP inhibitor antitumour activity, and (c) long-term toxicities (Liu and Matulonis, 2014). High clinical research priorities should be aimed to better understand whether PARP inhibitors are best used (a) as actual treatment of recurrent disease or as maintenance therapy, (b) before or after platinum-based therapy, (c) as single agents or in combination with chemotherapeutic or novel targeted agents. Furthermore, accurate definition of molecular features that reliably identify BRCAness will allow clinicians to extend the use of PARP inhibitors to non-BRCA-mutated OC. Novel combinations that warrant further clinical exploration include, but are not limited to, PI3-kinase inhibitors, angiogenesis inhibitors or ATM 
and cell cycle inhibitors (Weel inhibitor). A recent preclinical study showed that talazoparib exhibited immunoregulatory effects in a murine model providing a rational to evaluate a combination with an immune check point inhibitor (Huang et al, 2015). This rationale is further supported by the fact that HR deficiency is associated with genomic instability, and may therefore, also be associated with an increase in the expression of neoantigens and immunogenicity warranting the use of an immune check point inhibitor. Finally, comparative studies are needed to examine whether the preclinical differences in potency or mechanism of action among PARP inhibitor will have clinical implications. With completion of these ongoing efforts, PARP inhibitors are poised to help improve clinical outcomes for patients with $B R C A$-associated and sporadic OC.

\section{ACKNOWLEDGEMENTS}

Writing and editorial support provided by SCI Scientific Communications \& Information, Parsippany, NJ, Greg Tardie, PhD of the Lockwood Group, Stamford, CT, and Elizabeth Goodwin, PhD. (funded by AstraZeneca LP). The authors would like to extend their sincere thanks to Francesca Balordi, PhD; Stephanie Doerner, $\mathrm{PhD}$; and Greg Tardie, $\mathrm{PhD}$ of the Lockwood Group, and Creative Media Works, Pennington, NJ for the development of Figure 1. This work was supported by AstraZeneca LP.

\section{CONFLICT OF INTEREST}

GEK has received research grant support from Amgen, Novartis, Pfizer and has participated in advisory boards for Genentech, Clovis Oncology, and Medivation. RSK was involved in the development of rucaparib, participated in olaparib trials, and served an advisory role to Clovis Oncology.

\section{REFERENCES}

Abkevich V, Timms KM, Hennessy BT, Potter J, Carey MS, Meyer LA, SmithMcCune K, Broaddus R, Lu KH, Chen J, Tran TV, Williams D, Iliev D, Jammulapati S, FitzGerald LM, Krivak T, DeLoia JA, Gutin A, Mills GB, Lanchbury JS (2012) Patterns of genomic loss of heterozygosity predict homologous recombination repair defects in epithelial ovarian cancer. Br J Cancer 107(10): 1776-1782.

Alsop K, Fereday S, Meldrum C, deFazio A, Emmanuel C, George J, Dobrovic A, Birrer MJ, Webb PM, Stewart C, Friedlander M, Fox S, Bowtell D, Mitchell G (2012) BRCA mutation frequency and patterns of treatment response in BRCA mutation-positive women with ovarian cancer: a report from the Australian Ovarian Cancer Study Group. J Clin Oncol 30(21): 2654-2663.

Althaus FR, Richter C (1987) ADP-ribosylation of proteins. Enzymology and biological significance. Mol Biol Biochem Biophys 37: 1-237.

Ame JC, Rolli V, Schreiber V, Niedergang C, Apiou F, Decker P, Muller S, Hoger T, Menissier-de Murcia J, de Murcia G (1999) PARP-2, A novel mammalian DNA damage-dependent poly(ADP-ribose) polymerase. J Biol Chem 274(25): 17860-17868.

Ang JE, Gourley C, Powell CB, High H, Shapira-Frommer R, Castonguay V, De Greve J, Atkinson T, Yap TA, Sandhu S, Banerjee S, Chen LM, Friedlander ML, Kaufman B, Oza AM, Matulonis U, Barber LJ, Kozarewa I, Fenwick K, Assiotis I, Campbell J, Chen L, de Bono JS, Gore ME, Lord CJ, Ashworth A, Kaye SB (2013) Efficacy of chemotherapy in BRCA1/2 mutation carrier ovarian cancer in the setting of PARP inhibitor resistance: a multiinstitutional study. Clin Cancer Res 19(19): 5485-5493.

Antoniou A, Pharoah PD, Narod S, Risch HA, Eyfjord JE, Hopper JL, Loman N, Olsson H, Johannsson O, Borg A, Pasini B, Radice P, Manoukian S, Eccles DM, Tang N, Olah E, Anton-Culver H, Warner E, Lubinski J, Gronwald J, Gorski B, Tulinius H, Thorlacius S, Eerola H, Nevanlinna H, Syrjakoski K, Kallioniemi OP, Thompson D, Evans C, Peto J, Lalloo F, Evans DG, Easton DF (2003) Average risks of breast and ovarian cancer associated with BRCA1 or BRCA2 mutations detected in case Series unselected for family history: a combined analysis of 22 studies. Am J Hum Genet 72(5): 1117-1130.

Ashworth A (2008) A synthetic lethal therapeutic approach: poly(ADP) ribose polymerase inhibitors for the treatment of cancers deficient in DNA double-strand break repair. J Clin Oncol 26(22): 3785-3790.

Audeh MW, Carmichael J, Penson RT, Friedlander M, Powell B, Bell-McGuinn KM, Scott C, Weitzel JN, Oaknin A, Loman N, Lu K, Schmutzler RK, Matulonis U, Wickens M, Tutt A (2010) Oral poly (ADP-ribose) polymerase inhibitor olaparib in patients with BRCA1 or BRCA2 mutations and recurrent ovarian cancer: a proof-of-concept trial. Lancet 376(9737): 245-251.

Bell-McGuinn KM, Brady WE, Schilder RJ, Fracasso PM, Moore KN, Walker JL, Duska LR, Mathews CA, Chen A, Shepherd SP, Giranda VL, Aghajanian C (2015) A phase I study of continuous veliparib in combination with IV carboplatin/paclitaxel or IV/IP paclitaxel/cisplatin and bevacizumab in newly diagnosed patients with previously untreated epithelial ovarian, fallopian tube, or primary peritoneal cancer: An NRG Oncology/Gynecologic Oncology Group study. J Clin Oncol 33(suppl): abstr 5507.

Bhatia S (2013) Therapy-related myelodysplasia and acute myeloid leukemia. Semin Oncol 40(6): 666-675.

Bindra RS, Gibson SL, Meng A, Westermark U, Jasin M, Pierce AJ, Bristow RG, Classon MK, Glazer PM (2005) Hypoxia-induced down-regulation of BRCA1 expression by E2Fs. Cancer Res 65(24): 11597-11604.

Bindra RS, Schaffer PJ, Meng A, Woo J, Maseide K, Roth ME, Lizardi P, Hedley DW, Bristow RG, Glazer PM (2004) Down-regulation of Rad51 and decreased homologous recombination in hypoxic cancer cells. Mol Cell Biol 24(19): 8504-8518.

Birkbak NJ, Wang ZC, Kim JY, Eklund AC, Li Q, Tian R, Bowman-Colin C, Li Y, Greene-Colozzi A, Iglehart JD, Tung N, Ryan PD, Garber JE, Silver DP, Szallasi Z, Richardson AL (2012) Telomeric allelic imbalance indicates defective DNA repair and sensitivity to DNA-damaging agents. Cancer Discov 2(4): 366-375.

Bolton KL, Chenevix-Trench G, Goh C, Sadetzki S, Ramus SJ, Karlan BY, Lambrechts D, Despierre E, Barrowdale D, McGuffog L, Healey S, Easton DF, Sinilnikova O, Benitez J, Garcia MJ, Neuhausen S, Gail MH, Hartge P, Peock S, Frost D, Evans DG, Eeles R, Godwin AK, Daly MB, Kwong A, Ma ES, Lazaro C, Blanco I, Montagna M, D’Andrea E, Nicoletto MO, Johnatty SE, Kjaer SK, Jensen A, Hogdall E, Goode EL, Fridley BL, Loud JT, Greene MH, Mai PL, Chetrit A, Lubin F, Hirsh-Yechezkel G, Glendon G, Andrulis IL, Toland AE, Senter L, Gore ME, Gourley C, Michie CO, Song H, Tyrer J, Whittemore AS, McGuire V, Sieh W, Kristoffersson U, Olsson H, Borg A, Levine DA, Steele L, Beattie MS, Chan S, Nussbaum RL, Moysich KB, Gross J, Cass I, Walsh C, Li AJ, Leuchter R, Gordon O, Garcia-Closas M, Gayther SA, Chanock SJ, Antoniou AC, Pharoah PD (2012) Association between BRCA1 and BRCA2 mutations and survival in women with invasive epithelial ovarian cancer. JAMA 307(4): 382-390.

Bryant HE, Petermann E, Schultz N, Jemth AS, Loseva O, Issaeva N, Johansson F, Fernandez S, McGlynn P, Helleday T (2009) PARP is activated at stalled forks to mediate Mre11-dependent replication restart and recombination. EMBO J 28(17): 2601-2615.

Bryant HE, Schultz N, Thomas HD, Parker KM, Flower D, Lopez E, Kyle S, Meuth M, Curtin NJ, Helleday T (2005) Specific killing of BRCA2deficient tumours with inhibitors of poly(ADP-ribose) polymerase. Nature 434(7035): 913-917.

Burkle A (2001) Physiology and pathophysiology of poly(ADP-ribosyl)ation. Bioessays 23(9): 795-806.

Byrski T, Gronwald J, Huzarski T, Grzybowska E, Budryk M, Stawicka M, Mierzwa T, Szwiec M, Wisniowski R, Siolek M, Dent R, Lubinski J, Narod S (2010) Pathologic complete response rates in young women with BRCA1-positive breast cancers after neoadjuvant chemotherapy. J Clin Oncol 28(3): 375-379.

Caldecott KW (2008) Single-strand break repair and genetic disease. Nat Rev Genet 9(8): 619-631.

Cancer Genome Atlas Research Network (2011) Integrated genomic analyses of ovarian carcinoma. Nature 474(7353): 609-615.

Chan N, Pires IM, Bencokova Z, Coackley C, Luoto KR, Bhogal N, Lakshman M, Gottipati P, Oliver FJ, Helleday T, Hammond EM, Bristow RG (2010) Contextual synthetic lethality of cancer cell kill based on the tumor microenvironment. Cancer Res 70(20): 8045-8054.

Chapman JR, Barral P, Vannier JB, Borel V, Steger M, Tomas-Loba A, Sartori AA, Adams IR, Batista FD, Boulton SJ (2013) RIF1 is essential for 
53BP1-dependent nonhomologous end joining and suppression of DNA double-strand break resection. Mol Cell 49(5): 858-871.

Chapman JR, Taylor MR, Boulton SJ (2012) Playing the end game: DNA double-strand break repair pathway choice. Mol Cell 47(4): 497-510.

Chen S, Parmigiani G (2007) Meta-analysis of BRCA1 and BRCA2 penetrance. J Clin Oncol 25(11): 1329-1333.

Chetrit A, Hirsh-Yechezkel G, Ben-David Y, Lubin F, Friedman E, Sadetzki S (2008) Effect of BRCA1/2 mutations on long-term survival of patients with invasive ovarian cancer: the national Israeli study of ovarian cancer. J Clin Oncol 26(1): 20-25.

Ciccia A, Elledge SJ (2010) The DNA damage response: making it safe to play with knives. Mol Cell 40(2): 179-204.

Clovis Oncology (2015) Rucaparib [prescribing information]. Available at http://clovisoncology.com/products-companion-diagnostics/rucaparib/.

Coleman RL, Sill MW, Bell-McGuinn K, Aghajanian C, Gray HJ, Tewari KS, Rubin SC, Rutherford TJ, Chan JK, Chen A, Swisher EM (2015) A phase II evaluation of the potent, highly selective PARP inhibitor veliparib in the treatment of persistent or recurrent epithelial ovarian, fallopian tube, or primary peritoneal cancer in patients who carry a germline BRCA1 or BRCA2 mutation - An NRG Oncology/Gynecologic Oncology Group study. Gynecol Oncol 137(3): 386-391.

Coleman RL, Swisher EM, Oza AM, Scott CL, Giordano H, Lin KK, Konecny GE, Tinker A, O’Malley DM, Kristeleit RS, Ma L, Bell-McGuinn KM, Brenton JD, Cragun JM, Oaknin A, Ray-Coquard IL, Kaufmann SH, Goble S, Maloney L, McNeish IA (2016) Refinement of prespecified cutoff for genomic loss of heterozygosity (LOH) in ARIEL2 part 1: A phase II study of rucaparib in patients (pts) with high grade ovarian carcinoma (HGOC). J Clin Oncol 34(suppl): Abstract 5540.

Curtin N (2014) PARP inhibitors for anticancer therapy. Biochem Soc Trans 42(1): 82-88.

Curtin NJ (2012) DNA repair dysregulation from cancer driver to therapeutic target. Nat Rev Cancer 12(12): 801-817.

De Bono JS, Mina LA, Gonzalez M, Curtin NJ, Wang E, Henshaw JW, Chadha M, Sachdev JC, Matei D, Jameson GS, Ong M, Basu B, Wainberg ZA, Byers LA, Chugh R, Dorr A, Kaye SB, Ramanathan RK (2013) First in human trial of novel oral PARP inhibitor BMN 673 in patients with solid tumors. J Clin Oncol 31(suppl 15): abstract 2580.

De Lorenzo SB, Patel AG, Hurley RM, Kaufmann SH (2013) The elephant and the blind men: making sense of PARP inhibitors in homologous recombination deficient tumor cells. Front Oncol 3: 228.

de Murcia JM, Niedergang C, Trucco C, Ricoul M, Dutrillaux B, Mark M, Oliver FJ, Masson M, Dierich A, LeMeur M, Walztinger C, Chambon P, de Murcia G (1997) Requirement of poly(ADP-ribose) polymerase in recovery from DNA damage in mice and in cells. Proc Natl Acad Sci USA 94(14): 7303-7307.

Del Conte G, Sessa C, von Moos R, Vigano L, Digena T, Locatelli A, Gallerani E, Fasolo A, Tessari A, Cathomas R, Gianni L (2014) Phase I study of olaparib in combination with liposomal doxorubicin in patients with advanced solid tumours. Br J Cancer 111(4): 651-659.

Di Virgilio M, Callen E, Yamane A, Zhang W, Jankovic M, Gitlin AD, Feldhahn N, Resch W, Oliveira TY, Chait BT, Nussenzweig A, Casellas R, Robbiani DF, Nussenzweig MC (2013) Rif1 prevents resection of DNA breaks and promotes immunoglobulin class switching. Science 339(6120): 711-715.

Domchek SM, Aghajanian C, Shapira-Frommer R, Schmutzler RK, Audeh MW, Friedlander M, Balmaña J, Mitchell G, Fried G, Stemmer SM, Hubert A, Rosengarten O, Loman N, Robertson JD, Mann H, Kaufman B (2016) Efficacy and safety of olaparib monotherapy in germline BRCA1/2 mutation carriers with advanced ovarian cancer and three or more lines of prior therapy. Gynecol Oncol 140(2): 199-203.

Drew Y, Ledermann J, Hall G, Rea D, Glasspool R, Highley M, Jayson G, Sludden J, Murray J, Jamieson D, Halford S, Acton G, Backholer Z, Mangano R, Boddy A, Curtin N, Plummer R (2016) Phase 2 multicentre trial investigating intermittent and continuous dosing schedules of the poly(ADP-ribose) polymerase inhibitor rucaparib in germline BRCA mutation carriers with advanced ovarian and breast cancer. Br J Cancer 114(7): 723-730.

Edwards SL, Brough R, Lord CJ, Natrajan R, Vatcheva R, Levine DA, Boyd J, Reis-Filho JS, Ashworth A (2008) Resistance to therapy caused by intragenic deletion in BRCA2. Nature 451(7182): 1111-1115.

Escribano-Diaz C, Orthwein A, Fradet-Turcotte A, Xing M, Young JT, Tkac J, Cook MA, Rosebrock AP, Munro M, Canny MD, Xu D, Durocher D (2013) A cell cycle-dependent regulatory circuit composed of 53BP1-RIF1 and BRCA1-CtIP controls DNA repair pathway choice. Mol Cell 49(5): 872-883.

Farmer H, McCabe N, Lord CJ, Tutt AN, Johnson DA, Richardson TB, Santarosa M, Dillon KJ, Hickson I, Knights C, Martin NM, Jackson SP, Smith GC, Ashworth A (2005) Targeting the DNA repair defect in BRCA mutant cells as a therapeutic strategy. Nature 434(7035): 917-921.

Fong PC, Boss DS, Yap TA, Tutt A, Wu P, Mergui-Roelvink M, Mortimer P, Swaisland H, Lau A, O'Connor MJ, Ashworth A, Carmichael J, Kaye SB, Schellens JH, de Bono JS (2009) Inhibition of poly(ADP-ribose) polymerase in tumors from BRCA mutation carriers. N Engl J Med 361(2): 123-134.

Fong PC, Yap TA, Boss DS, Carden CP, Mergui-Roelvink M, Gourley C, De Greve J, Lubinski J, Shanley S, Messiou C, A'Hern R, Tutt A, Ashworth A, Stone J, Carmichael J, Schellens JH, de Bono JS, Kaye SB (2010) Poly(ADP)ribose polymerase inhibition: frequent durable responses in BRCA carrier ovarian cancer correlating with platinum-free interval. J Clin Oncol 28(15): 2512-2519.

Friedman LS, Ostermeyer EA, Szabo CI, Dowd P, Lynch ED, Rowell SE, King MC (1994) Confirmation of BRCA1 by analysis of germline mutations linked to breast and ovarian cancer in ten families. Nat Genet 8(4): 399-404.

Gelmon KA, Tischkowitz M, Mackay H, Swenerton K, Robidoux A, Tonkin K, Hirte H, Huntsman D, Clemons M, Gilks B, Yerushalmi R, Macpherson E, Carmichael J, Oza A (2011) Olaparib in patients with recurrent high-grade serous or poorly differentiated ovarian carcinoma or triple-negative breast cancer: a phase 2, multicentre, open-label, non-randomised study. Lancet Oncol 12(9): 852-861.

Gorrini C, Baniasadi PS, Harris IS, Silvester J, Inoue S, Snow B, Joshi PA, Wakeham A, Molyneux SD, Martin B, Bouwman P, Cescon DW, Elia AJ, Winterton-Perks Z, Cruickshank J, Brenner D, Tseng A, Musgrave M, Berman HK, Khokha R, Jonkers J, Mak TW, Gauthier ML (2013) BRCA1 interacts with $\mathrm{Nrf} 2$ to regulate antioxidant signaling and cell survival. J Exp Med 210(8): 1529-1544.

Gorrini C, Gang BP, Bassi C, Wakeham A, Baniasadi SP, Hao Z, Li WY, Cescon DW, Li YT, Molyneux S, Penrod N, Lupien M, Schmidt EE, Stambolic V, Gauthier ML, Mak TW (2014) Estrogen controls the survival of BRCA1-deficient cells via a PI3K-NRF2-regulated pathway. Proc Natl Acad Sci USA 111(12): 4472-4477.

Gudmundsdottir K, Ashworth A (2006) The roles of BRCA1 and BRCA2 and associated proteins in the maintenance of genomic stability. Oncogene 25(43): 5864-5874.

Haince JF, McDonald D, Rodrigue A, Dery U, Masson JY, Hendzel MJ, Poirier GG (2008) PARP1-dependent kinetics of recruitment of MRE11 and NBS1 proteins to multiple DNA damage sites. J Biol Chem 283(2): $1197-1208$.

Haluska P, Timms KM, AlHilli M, Wang Y, Hartman AM, Jones J, Gutin A, Sangale Z, Neff C, Lynchbury J, Rudolph-Owen L, Becker MA, Agarwal S, Wilcoxen KM (2014) Homologous recombination deficiency (HRD) score and niraparib efficacy in high grade ovarian cancer (abstract 214). Eur J Cancer 50(suppl 6): 72-73.

Hassler M, Ladurner AG (2012) Towards a structural understanding of PARP1 activation and related signalling ADP-ribosyl-transferases. Curr Opin Struct Biol 22(6): 721-729.

Helleday T (2011) The underlying mechanism for the PARP and BRCA synthetic lethality: clearing up the misunderstandings. Mol Oncol 5(4): 387-393.

Helleday T, Bryant HE, Schultz N (2005) Poly(ADP-ribose) polymerase (PARP-1) in homologous recombination and as a target for cancer therapy. Cell Cycle 4(9): 1176-1178.

Hopkins TA, Shi Y, Rodriguez LE, Solomon LR, Donawho CK, DiGiammarino EL, Panchal SC, Wilsbacher JL, Gao W, Olson AM, Stolarik DF, Osterling DJ, Johnson EF, Maag D (2015) Mechanistic dissection of PARP1 trapping and the impact on in vivo tolerability and efficacy of PARP inhibitors. Mol Cancer Res 13(11): 1465-1477.

Horton JK, Stefanick DF, Prasad R, Gassman NR, Kedar PS, Wilson SH (2014) Base excision repair defects invoke hypersensitivity to PARP inhibition. Mol Cancer Res 12(8): 1128-1139.

Hu Y, Petit SA, Ficarro SB, Toomire KJ, Xie A, Lim E, Cao SA, Park E, Eck MJ, Scully R, Brown M, Marto JA, Livingston DM (2014) PARP1driven poly-ADP-ribosylation regulates BRCA1 function in homologous recombination-mediated DNA repair. Cancer Discov 4(12): 1430-1447.

Huang J, Wang L, Cong Z, Amoozgar Z, Kiner E, Xing D, Orsulic S, Matulonis U, Goldberg MS (2015) The PARP1 inhibitor BMN 673 exhibits 
immunoregulatory effects in a Brcal(-/-) murine model of ovarian cancer. Biochem Biophys Res Commun 463(4): 551-556.

Ibrahim YH, Garcia-Garcia C, Serra V, He L, Torres-Lockhart K, Prat A, Anton P, Cozar P, Guzman M, Grueso J, Rodriguez O, Calvo MT, Aura C, Diez O, Rubio IT, Perez J, Rodon J, Cortes J, Ellisen LW, Scaltriti M, Baselga J (2012) PI3K inhibition impairs BRCA1/2 expression and sensitizes BRCA-proficient triple-negative breast cancer to PARP inhibition. Cancer Discov 2(11): 1036-1047.

Jaspers JE, Kersbergen A, Boon U, Sol W, van Deemter L, Zander SA, Drost R, Wientjens E, Ji J, Aly A, Doroshow JH, Cranston A, Martin NM, Lau A, O'Connor MJ, Ganesan S, Borst P, Jonkers J, Rottenberg S (2013) Loss of 53BP1 causes PARP inhibitor resistance in Brcal-mutated mouse mammary tumors. Cancer Discov 3(1): 68-81.

Juvekar A, Burga LN, Hu H, Lunsford EP, Ibrahim YH, Balmana J, Rajendran A, Papa A, Spencer K, Lyssiotis CA, Nardella C, Pandolfi PP, Baselga J, Scully R, Asara JM, Cantley LC, Wulf GM (2012) Combining a PI3K inhibitor with a PARP inhibitor provides an effective therapy for BRCA1-related breast cancer. Cancer Discov 2(11): 1048-1063.

Karanam K, Kafri R, Loewer A, Lahav G (2012) Quantitative live cell imaging reveals a gradual shift between DNA repair mechanisms and a maximal use of HR in mid S phase. Mol Cell 47(2): 320-329.

Kaufman B, Shapira-Frommer R, Schmutzler RK, Audeh MW, Friedlander M, Balmana J, Mitchell G, Fried G, Stemmer SM, Hubert A, Rosengarten O, Steiner M, Loman N, Bowen K, Fielding A, Domchek SM (2015) Olaparib monotherapy in patients with advanced cancer and a germline BRCA1/2 mutation. J Clin Oncol 33(3): 244-250.

Kaye SB, Lubinski J, Matulonis U, Ang JE, Gourley C, Karlan BY, Amnon A, Bell-McGuinn KM, Chen LM, Friedlander M, Safra T, Vergote I, Wickens M, Lowe ES, Carmichael J, Kaufman B (2012) Phase II, open-label, randomized, multicenter study comparing the efficacy and safety of olaparib, a poly (ADP-ribose) polymerase inhibitor, and pegylated liposomal doxorubicin in patients with BRCA1 or BRCA2 mutations and recurrent ovarian cancer. J Clin Oncol 30(4): 372-379.

Kim MY, Zhang T, Kraus WL (2005) Poly(ADP-ribosyl)ation by PARP-1: 'PAR-laying' NAD + into a nuclear signal. Genes Dev 19(17): 1951-1967.

Konstantinopoulos PA, Ceccaldi R, Shapiro GI, D'Andrea AD (2015) Homologous recombination deficiency: exploiting the fundamental vulnerability of ovarian cancer. Cancer Discov 5(11): 1137-1154.

Kristeleit RS, Burris H, LoRusso P, Patel MR, Asghar US, El-Khouly F, Calvert AH, Infante JR, Hilton JF, Tolaney SM, Kittaneh M, Giordano H, Borrow J, Jaw-Tasi S, Shapiro G (2014) Phase 1/2 study of oral rucaparib: final phase 1 results. J Clin Oncol 32(suppl 5): abstr 2573.

Kummar S, Ji J, Morgan R, Lenz HJ, Puhalla SL, Belani CP, Gandara DR, Allen D, Kiesel B, Beumer JH, Newman EM, Rubinstein L, Chen A, Zhang Y, Wang L, Kinders RJ, Parchment RE, Tomaszewski JE, Doroshow JH (2012) A phase I study of veliparib in combination with metronomic cyclophosphamide in adults with refractory solid tumors and lymphomas. Clin Cancer Res 18(6): $1726-1734$.

Ledermann J, Harter P, Gourley C, Friedlander M, Vergote I, Rustin G, Scott C, Meier W, Shapira-Frommer R, Safra T, Matei D, Macpherson E, Watkins C, Carmichael J, Matulonis U (2012) Olaparib maintenance therapy in platinum-sensitive relapsed ovarian cancer. N Engl J Med 366(15): 1382-1392.

Ledermann J, Harter P, Gourley C, Friedlander M, Vergote I, Rustin G, Scott CL, Meier W, Shapira-Frommer R, Safra T, Matei D, Fielding A, Spencer S, Dougherty B, Orr M, Hodgson D, Barrett JC, Matulonis U (2014) Olaparib maintenance therapy in patients with platinum-sensitive relapsed serous ovarian cancer: a preplanned retrospective analysis of outcomes by BRCA status in a randomised phase 2 trial. Lancet Oncol 15(8): 852-861.

Ledermann JA, Harter P, Gourley C, Friedlander M, Vergote I, Rustin GJS, Scott CL, Meier W, Shapira-Frommer R, Safra T, Matei DE, Fielding A, Spencer S, Rowe P, Lowe ES, Matulonis UA (2016) Overall survival (OS) in patients (pts) with platinum-sensitive relapsed serous ovarian cancer (PSR SOC) receiving olaparib maintenance monotherapy: An interim analysis. J Clin Oncol 34(suppl): abstract 5501.

Lee JM, Ledermann JA, Kohn EC (2014) PARP Inhibitors for BRCA1/2 mutation-associated and BRCA-like malignancies. Ann Oncol 25(1): $32-40$.

Li M, Yu X (2013) Function of BRCA1 in the DNA damage response is mediated by ADP-ribosylation. Cancer Cell 23(5): 693-704.
Li N, Alam J, Venkatesan MI, Eiguren-Fernandez A, Schmitz D, Di Stefano E, Slaughter N, Killeen E, Wang X, Huang A, Wang M, Miguel AH, Cho A, Sioutas C, Nel AE (2004) Nrf2 is a key transcription factor that regulates antioxidant defense in macrophages and epithelial cells: protecting against the proinflammatory and oxidizing effects of diesel exhaust chemicals. J Immunol 173(5): 3467-3481.

Lieber MR (2010) The mechanism of double-strand DNA break repair by the nonhomologous DNA end-joining pathway. Annu Rev Biochem 79: $181-211$.

Liu J, Matulonis UA (2014) New strategies in ovarian cancer: translating the molecular complexity of ovarian cancer into treatment advances. Clin Cancer Res 20(20): 5150-5156.

Liu JF, Barry WT, Birrer M, Lee JM, Buckanovich RJ, Fleming GF, Rimel B, Buss MK, Nattam S, Hurteau J, Luo W, Quy P, Whalen C, Obermayer L, Lee H, Winer EP, Kohn EC, Ivy SP, Matulonis UA (2014) Combination cediranib and olaparib versus olaparib alone for women with recurrent platinum-sensitive ovarian cancer: a randomised phase 2 study. Lancet Oncol 15(11): 1207-1214.

Lynparza prescribing information (2014) Lynparza [package insert] Wilmington, DEAstraZeneca Pharmaceuticals LPAvailable at http:// www.azpicentral.com/Lynparza/pi_lynparza.pdf\#page=1.

Malanga M, Althaus FR (2004) Poly(ADP-ribose) reactivates stalled DNA topoisomerase I and Induces DNA strand break resealing. J Biol Chem 279(7): 5244-5248.

Masson M, Niedergang C, Schreiber V, Muller S, Menissier-de Murcia J, de Murcia G (1998) XRCC1 is specifically associated with poly (ADP-ribose) polymerase and negatively regulates its activity following DNA damage. Mol Cell Biol 18(6): 3563-3571.

Mateo J, Moreno V, Gupta A, Kaye SB, Dean E, Middleton MR, Friedlander M, Gourley C, Plummer R, Rustin G, Sessa C, Leunen K, Ledermann J, Swaisland H, Fielding A, Bannister W, Nicum S, Molife LR (2016) An adaptive study to determine the optimal dose of the tablet formulation of the PARP inhibitor olaparib. Target Oncol 11(3): 401-415.

Mateo J, Friedlander M, Sessa C, Leunen K, Nicum S, Gourley C, Fielding A, Bowen K, Kaye S, Molife LR (2013) Administration of continuous/ intermittent olaparib in ovarian cancer patients with a germline BRCA1/2 mutation to determine an optimal dosing schedule for the tablet formulation (abstract). Eur J Cancer 49: S161.

Matulonis U, Mahner S, Wenham RM, Lederman JA, Monk BJ, Del Campo JM, Berek JS, Vergote I, Fabbro M, Katsaros D, Marth C, Lorusso D, Herrstedt J, Agarwal S, Martell RE, Mirza MR (2014) A phase 3 randomized doubleblind trial of maintenance with niraparib versus placebo in patients with platinum-sensitive ovarian cancer (ENGOT-OV16/NOVA trial). J Clin Oncol 32(suppl 5): Abstract TPS5625.

Matulonis UA, Penson RT, Domchek SM, Kaufman B, Shapira-Frommer R, Audeh MW, Kaye S, Molife LR, Gelmon KA, Robertson JD, Mann H, Ho TW, Coleman RL (2016) Olaparib monotherapy in patients with advanced relapsed ovarian cancer and a germline BRCA1/2 mutation: a multi-study analysis of response rates and safety. Ann Oncol 27(6): 1013-1019.

Matulonis UA, Wulf G, Barry W, Birrer M, Westin S, Spagnoletti T, McGuinn KB, Obermayer E, Whalen C, Aghajanian C, Solit D, Mills G, Cantley L (2015) Phase I of oral BKM120 or BYL719 and olaparib for highgrade serous ovarian cancer or triplenegative breast cancer: Final results of the BKM120 plus olaparib cohort. Cancer Res 75(suppl 15): abstract CT324.

McNeish I, A.M. O, Coleman RL, Scott C, Konecny GE, Tinker A, O’Malley DM, Brenton J, R.S. K, McGuinn KB, Oaknin A, Leary A, Lin K, Raponi M, S.H. G, Goble S, Rolfe L, Yelensky R, Allen AR, Swisher E (2015) Results of ARIEL2: a phase 2 trial to prospectively identify ovarian cancer patients likely to respond to rucaparib using tumor genetic analysis. J Clin Oncol 33(suppl): abstract 5508 .

Mendoza-Alvarez H, Alvarez-Gonzalez R (1993) Poly(ADP-ribose) polymerase is a catalytic dimer and the automodification reaction is intermolecular. J Biol Chem 268(30): 22575-22580.

Mendoza-Alvarez H, Alvarez-Gonzalez R (2004) The $40 \mathrm{kDa}$ carboxyterminal domain of poly(ADP-ribose) polymerase-1 forms catalytically competent homo- and heterodimers in the absence of DNA. J Mol Biol 336(1): 105-114.

Michalarea V, Lorente D, Lopez J, Carreira S, Hassam H, Parmar M, Sathiyayogan N, Turner A, Hall E, Fandos SS, Seeramreddi S, Decordova S, Swales K, Ruddle R, Raynaud F, Tunariu N, Attard G, Molife IR, Banerji U, Plummer R, de Bono JS, Yap TA (2015) 
Accelerated phase I trial of two schedules of the combination of the PARP inhibitor olaparib and AKT inhibitor AZD5363 using a novel intrapatient dose escalation design in advanced cancer patients. Cancer Res 75(suppl 15): Abstract CT323.

Miki Y, Swensen J, Shattuck-Eidens D, Futreal PA, Harshman K, Tavtigian S, Liu Q, Cochran C, Bennett LM, Ding W, Bell B, Rosenthal J, Hussey C, Tran T, McClure M, Frye C, Hattier T, Phelps R, Haugen-Strano A, Katcher H, Yakumo K, Gholami Z, Shaffer S, Stone S, Bayer S, Wray W, Bogden R, Dayananth P, Ward P, Tonin P, Narod S, Bristow PK, Norris FH, Helvering L, Morrison P, Rosteck P, Lai M, Barrett JC, Lewis C, Neuhausen S, Cannon-Albright L, Goldgar D, Wiseman R, Kamb A, Skolnick MH (1994) A strong candidate for the breast and ovarian cancer susceptibility gene BRCA1. Science 266(5182): 66-71.

Moore KN, DiSilvestro P, Lowe ES, Garnett S, Pujade-Lauraine E (2014) SOLO1 and SOLO2: Randomized phase III trials of olaparib in patients (pts) with ovarian cancer and a BRCA1/2 mutation (BRCAm). J Clin Oncol 32(suppl 5): abstract TPS5616.

Moslehi R, Chu W, Karlan B, Fishman D, Risch H, Fields A, Smotkin D, Ben-David Y, Rosenblatt J, Russo D, Schwartz P, Tung N, Warner E, Rosen B, Friedman J, Brunet JS, Narod SA (2000) BRCA1 and BRCA2 mutation analysis of 208 Ashkenazi Jewish women with ovarian cancer. Am J Hum Genet 66(4): 1259-1272.

Murai J, Huang SY, Das BB, Renaud A, Zhang Y, Doroshow JH, Ji J, Takeda S, Pommier Y (2012) Trapping of PARP1 and PARP2 by clinical PARP inhibitors. Cancer Res 72(21): 5588-5599.

Murai J, Huang SY, Renaud A, Zhang Y, Ji J, Takeda S, Morris J, Teicher B, Doroshow JH, Pommier Y (2014) Stereospecific PARP trapping by BMN 673 and comparison with olaparib and rucaparib. Mol Cancer Ther 13(2): 433-443.

National Cancer Institute (2015a) Surveillance, Epidemiology, and End Results Program, Breast. Available at http://seer.cancer.gov/statfacts/html/ breast.html.

National Cancer Institute (2015b) Surveillance, Epidemiology, and End Results Program, Ovary. Available at http://seer.cancer.gov/statfacts/html/ ovary.html.

Neuhausen SL, Ozcelik H, Southey MC, John EM, Godwin AK, Chung W, Iriondo-Perez J, Miron A, Santella RM, Whittemore A, Andrulis IL, Buys SS, Daly MB, Hopper JL, Seminara D, Senie RT, Terry MB. Breast Cancer Family R (2009) BRCA1 and BRCA2 mutation carriers in the Breast Cancer Family Registry: an open resource for collaborative research. Breast Cancer Res Treat 116(2): 379-386.

O'Sullivan CC, Moon DH, Kohn EC, Lee JM (2014) Beyond breast and ovarian cancers: PARP Inhibitors for BRCA mutation-associated and BRCA-like solid tumors. Front Oncol 4: 42.

Odell ID, Wallace SS, Pederson DS (2013) Rules of engagement for base excision repair in chromatin. J Cell Physiol 228(2): 258-266.

Oza AM, Cibula D, Benzaquen AO, Poole C, Mathijssen RH, Sonke GS, Colombo N, Spacek J, Vuylsteke P, Hirte H, Mahner S, Plante M, Schmalfeldt B, Mackay H, Rowbottom J, Lowe ES, Dougherty B, Barrett JC, Friedlander M (2015) Olaparib combined with chemotherapy for recurrent platinum-sensitive ovarian cancer: a randomised phase 2 trial. Lancet Oncol 16(1): 87-97.

Patel AG, De Lorenzo SB, Flatten KS, Poirier GG, Kaufmann SH (2012) Failure of iniparib to inhibit poly(ADP-Ribose) polymerase in vitro. Clin Cancer Res 18(6): 1655-1662.

Patel AG, Sarkaria JN, Kaufmann SH (2011) Nonhomologous end joining drives poly(ADP-ribose) polymerase (PARP) inhibitor lethality in homologous recombination-deficient cells. Proc Natl Acad Sci USA 108(8): 3406-3411.

Polo SE, Jackson SP (2011) Dynamics of DNA damage response proteins at DNA breaks: a focus on protein modifications. Genes Dev 25(5): 409-433.

Popova T, Manie E, Rieunier G, Caux-Moncoutier V, Tirapo C, Dubois T, Delattre O, Sigal-Zafrani B, Bollet M, Longy M, Houdayer C, Sastre-Garau X, Vincent-Salomon A, Stoppa-Lyonnet D, Stern MH (2012) Ploidy and largescale genomic instability consistently identify basal-like breast carcinomas with BRCA1/2 inactivation. Cancer Res 72(21): 5454-5462.

Pyriochou A, Olah G, Deitch EA, Szabo C, Papapetropoulos A (2008) Inhibition of angiogenesis by the poly(ADP-ribose) polymerase inhibitor PJ-34. Int J Mol Med 22(1): 113-118.

Ramus SJ, Gayther SA (2009) The contribution of BRCA1 and BRCA2 to ovarian cancer. Mol Oncol 3(2): 138-150.

Realini CA, Althaus FR (1992) Histone shuttling by poly(ADP-ribosylation). J Biol Chem 267(26): 18858-18865.
Robert I, Dantzer F, Reina-San-Martin B (2009) Parp1 facilitates alternative NHEJ, whereas Parp2 suppresses IgH/c-myc translocations during immunoglobulin class switch recombination. J Exp Med 206(5): 1047-1056.

Rottenberg S, Jaspers JE, Kersbergen A, van der Burg E, Nygren AO, Zander SA, Derksen PW, de Bruin M, Zevenhoven J, Lau A, Boulter R, Cranston A, O'Connor MJ, Martin NM, Borst P, Jonkers J (2008) High sensitivity of BRCA1-deficient mammary tumors to the PARP inhibitor AZD2281 alone and in combination with platinum drugs. Proc Natl Acad Sci USA 105(44): 17079-17084.

Rouleau M, Patel A, Hendzel MJ, Kaufmann SH, Poirier GG (2010) PARP inhibition: PARP1 and beyond. Nat Rev Cancer 10(4): 293-301.

Rulten SL, Fisher AE, Robert I, Zuma MC, Rouleau M, Ju L, Poirier G, Reina-San-Martin B, Caldecott KW (2011) PARP-3 and APLF function together to accelerate nonhomologous end-joining. Mol Cell 41(1): 33-45.

Sandhu SK, Schelman WR, Wilding G, Moreno V, Baird RD, Miranda S, Hylands L, Riisnaes R, Forster M, Omlin A, Kreischer N, Thway K, Gevensleben H, Sun L, Loughney J, Chatterjee M, Toniatti C, Carpenter CL, Iannone R, Kaye SB, de Bono JS, Wenham RM (2013) The poly(ADP-ribose) polymerase inhibitor niraparib (MK4827) in BRCA mutation carriers and patients with sporadic cancer: a phase 1 dose-escalation trial. Lancet Oncol 14(9): 882-892.

Satoh MS, Lindahl T (1992) Role of poly(ADP-ribose) formation in DNA repair. Nature 356(6367): 356-358.

Schmid BC, Oehler MK (2014) New perspectives in ovarian cancer treatment. Maturitas 77(2): 128-136.

Schreiber V, Ame JC, Dolle P, Schultz I, Rinaldi B, Fraulob V, Menissier-de Murcia J, de Murcia G (2002) Poly(ADP-ribose) polymerase-2 (PARP-2) is required for efficient base excision DNA repair in association with PARP-1 and XRCC1. J Biol Chem 277(25): 23028-23036.

Schreiber V, Dantzer F, Ame JC, de Murcia G (2006) Poly(ADP-ribose): novel functions for an old molecule. Nat Rev Mol Cell Biol 7(7): 517-528.

Schultz N, Lopez E, Saleh-Gohari N, Helleday T (2003) Poly(ADP-ribose) polymerase (PARP-1) has a controlling role in homologous recombination. Nucleic Acids Res 31(17): 4959-4964.

Scott CL, Swisher EM, Kaufmann SH (2015) Poly (ADP-ribose) polymerase inhibitors: recent advances and future development. J Clin Oncol 33(12): 1397-1406.

Sehouli J, Braicu EI, Chekerov R (2016) PARP Inhibitors for Recurrent Ovarian Carcinoma: Current Treatment Options and Future Perspectives. Geburtshilfe Frauenheilkd 76(2): 164-169.

Sfakianos GP, Havrilesky LJ (2011) A review of cost-effectiveness studies in ovarian cancer. Cancer Control 18(1): 59-64.

Shapiro G, Kristeleit R, Middleton M, Burris HI, Molife R, Evans J, Wilson R, LoRusso P, Spicer J, Dieras V, Patel M, Dominy E, Simpson D, Giordano H, Allen A, Jaw-Tasi S, Plummer R (2013) Pharmacokinetics of orally administered rucaparib in patients with advanced solid tumors [abstract]. Mol Cancer Ther 12(suppl 11): A218.

Shen Y, Rehman FL, Feng Y, Boshuizen J, Bajrami I, Elliott R, Wang B, Lord CJ, Post LE, Ashworth A (2013) BMN 673, a novel and highly potent PARP1/2 inhibitor for the treatment of human cancers with DNA repair deficiency. Clin Cancer Res 19(18): 5003-5015.

Soni A, Siemann M, Grabos M, Murmann T, Pantelias GE, Iliakis G (2014) Requirement for Parp-1 and DNA ligases 1 or 3 but not of Xrcc1 in chromosomal translocation formation by backup end joining. Nucleic Acids Res 42(10): 6380-6392.

Sousa FG, Matuo R, Soares DG, Escargueil AE, Henriques JA, Larsen AK, Saffi J (2012) PARPs and the DNA damage response. Carcinogenesis 33(8): $1433-1440$

Stracker TH, Petrini JH (2011) The MRE11 complex: starting from the ends. Nat Rev Mol Cell Biol 12(2): 90-103.

Strom CE, Johansson F, Uhlen M, Szigyarto CA, Erixon K, Helleday T (2011) Poly (ADP-ribose) polymerase (PARP) is not involved in base excision repair but PARP inhibition traps a single-strand intermediate. Nucleic Acids Res 39(8): 3166-3175.

Swisher E, Brenton J, Kaufmann S, Oza A, Coleman RL, O’Malley D, Konecny GE, Ma L, Harrell M, Visscher D, Hendrickson AW, Lin K, Raponi M, Mann E, Giordano H, Maloney L, Rolfe L, McNeish I (2014) Updated clinical and preliminary correlative results of ARIEL2, a Phase 2 study to identify ovarian cancer patients likely to respond to rucaparib (abstract 215). Eur J Cancer 50(suppl 6): 73.

Swisher E, Brenton J, Kaufmann S, Oza A, Coleman RL, O’Malley D, Konecny GE, Ma L, Harrell M, Visscher D, Hendrickson AW, Lin K, 
Raponi M, Mann E, Giordano H, Rolfe L, Isaacson J, Yelensky R, Scott C, Allen A, McNeish I (2013) ARIEL2: A phase 2 study to prospectively identify ovarian cancer patients likely to respond to rucaparib [abstract]. In AACR-NCI-EORTC International Conference on Molecular Targets and Cancer Therapeutics. Boston, MA, USA.

Symington LS, Gautier J (2011) Double-strand break end resection and repair pathway choice. Annu Rev Genet 45: 247-271.

Timms K, Neff C, Abkevich V, Jones JT, Kolquist KA, Mirza M, Lanchbury J, Mikule K, Agarwal S, Hartman AR, Gutin A, Wilcoxen K (2015) DNA repair deficiencies in ovarian cancer: Genomic analysis of high grade serous ovarian tumors from the NOVA study [abstract 458]. Eur J Cancer 51(suppl 3): S97-S98.

Timms KM, Abkevich V, Hughes E, Neff C, Reid J, Morris B, Kalva S, Potter J, Tran TV, Chen J, Iliev D, Sangale Z, Tikishvili E, Perry M, Zharkikh A, Gutin A, Lanchbury JS (2014) Association of BRCA1/2 defects with genomic scores predictive of DNA damage repair deficiency among breast cancer subtypes. Breast Cancer Res 16(6): 475.

Trucco C, Oliver FJ, de Murcia G, Menissier-de Murcia J (1998) DNA repair defect in poly(ADP-ribose) polymerase-deficient cell lines. Nucleic Acids Res 26(11): 2644-2649.

Venkitaraman AR (2014) Cancer suppression by the chromosome custodians, BRCA1 and BRCA2. Science 343(6178): 1470-1475.

Wainberg ZA, Hecht JR, Konecny GE, Chmielowski B, Finn RS, Martinez D, Yonemoto L, Slamon DJ (2015) Safety and efficacy results from a phase 1 dose-escalation trial of the PARP inhibitor talazoparib (bmn-673) in combination with either temozolomide or irinotecan in patients with advanced malignancies (abstract 317). Eur J Cancer 51(3 Suppl): S60.
Wainberg ZA, Hecht JR, Konecny GE, Goldman JW, Sadeghi S, Chmielowski B, Singh A, Finn RS, Martinez D, Yonemoto L, Glaspy J, Slamon DJ (2016) Safety and efficacy results from a phase I dose-escalation trial of the PARP inhibitor talazoparib in combination with either temozolomide or irinotecan in patients with advanced malignancies (abstract CT011). Cancer Res 76(14 Suppl): CT011.

Wang M, Wu W, Wu W, Rosidi B, Zhang L, Wang H, Iliakis G (2006) PARP-1 and Ku compete for repair of DNA double strand breaks by distinct NHEJ pathways. Nucleic Acids Res 34(21): 6170-6182.

Wooster R, Bignell G, Lancaster J, Swift S, Seal S, Mangion J, Collins N, Gregory S, Gumbs C, Micklem G (1995) Identification of the breast cancer susceptibility gene BRCA2. Nature 378(6559): 789-792.

Yadav A, Kumar B, Teknos T, Kumar P (2011) Sorafenib enhances the antitumor effects of chemoradiation treatment by downregulating ERCC-1 and XRCC-1 DNA repair proteins. Mol Cancer Ther 10(7): 1241-1251.

Yap TA, Sandhu SK, Carden CP, de Bono JS (2011) Poly(ADP-ribose) polymerase (PARP) inhibitors: Exploiting a synthetic lethal strategy in the clinic. CA Cancer J Clin 61(1): 31-49.

Zimmermann M, Lottersberger F, Buonomo SB, Sfeir A, de Lange T (2013) 53BP1 regulates DSB repair using Rif1 to control 5' end resection. Science 339(6120): 700-704.

(c) (1) (2) This work is licensed under the Creative Commons BY ${ }_{\text {NG }}$ SA Attribution-Non-Commercial-Share Alike 4.0 International License. To view a copy of this license, visit http:// creativecommons.org/licenses/by-nc-sa/4.0/ 